\title{
Accelerated High-Yield Generation of Limb-Innervating Motor Neurons from Human Stem Cells
}

\author{
Mackenzie W. Amoroso, ${ }^{1,2 \star}$ Gist F. Croft, ${ }^{1,2 \star}$ Damian J. Williams, ${ }^{3}$ Sean 0’Keeffe, ${ }^{4}$ Monica A. Carrasco, ${ }^{4}$ Anne R. Davis, ${ }^{5}$ \\ Laurent Roybon, ${ }^{1,2}$ Derek H. Oakley, ${ }^{1,2}$ Tom Maniatis, ${ }^{4}$ Christopher E. Henderson, ${ }^{1,2}$ \\ and Hynek Wichterle ${ }^{1,2}$ \\ 1Project A.L.S./Jenifer Estess Laboratory for Stem Cell Research, New York, New York 10032; 2Departments of Pathology, Neurology, and Neuroscience, \\ Center for Motor Neuron Biology and Disease and Columbia Stem Cell Initiative, Columbia University, New York, New York 10032; ${ }^{3}$ Department of \\ Physiology and Cellular Biophysics, Columbia University, New York, New York 10032; ${ }^{4}$ Department of Biochemistry and Biophysics, Columbia University, \\ New York, New York 10032; 5 Department of Obstetrics and Gynecology, Columbia University Medical Center, New York, New York 10032
}

Human pluripotent stem cells are a promising source of differentiated cells for developmental studies, cell transplantation, disease modeling, and drug testing. However, their widespread use even for intensely studied cell types like spinal motor neurons is hindered by the long duration and low yields of existing protocols for in vitro differentiation and by the molecular heterogeneity of the populations generated. We report a combination of small molecules that within 3 weeks induce motor neurons at up to $50 \%$ abundance and with defined subtype identities of relevance to neurodegenerative disease. Despite their accelerated differentiation, motor neurons expressed combinations of HB9, ISL1, and column-specific markers that mirror those observed in vivo in human embryonic spinal cord. They also exhibited spontaneous and induced activity, and projected axons toward muscles when grafted into developing chick spinal cord. Strikingly, this novel protocol preferentially generates motor neurons expressing markers of limb-innervating lateral motor column motor neurons (FOXP1 ${ }^{+} / \mathrm{LHX3}^{-}$). Access to high-yield cultures of human limb-innervating motor neuron subtypes will facilitate in-depth study of motor neuron subtype-specific properties, disease modeling, and development of large-scale cell-based screening assays.

\section{Introduction}

Generation of specific cell types from human pluripotent stem cells in vitro has the potential to yield novel insights into human development and disease. Directed differentiation of stem cells into spinal motor neurons allows access to cells that cannot be sampled in living human subjects and paves the way to their use for molecular studies, drug testing, or for targeted cell replace-

Received Feb. 22, 2012; revised Oct. 28, 2012; accepted Nov. 7, 2012.

Author contributions: M.W.A., C.E.H., and H.W. designed research; M.W.A., G.F.C., D.J.W., S.O., and H.W. performed research; G.F.C., M.A.C., A.R.D., L.R., D.H.O., and T.M. contributed unpublished reagents/analytic tools; M.W.A., D.J.W., and H.W. analyzed data; M.W.A., C.E.H., and H.W. wrote the paper.

This work was supported by Project A.L.S., P ${ }^{2}$ ALS, National Institutes of Health (NIH) GO Grant 5 RC2 NS06939502, NYSTEM Grant C024415, and the Dr. Leigh G. Cascarilla Postdoctoral Fellowship in Stem Cell Research (L.R). NIH DP10D003930 (T.M.); the ALS Association (M.A.C.); and The ALS Therapy Alliance (S.0.). We thank Amy MacDermott for introducing calcium-imaging approaches into our work and Kevin Eggan for open sharing of reagents and ideas throughout this study. We are grateful to F.P. Di Giorgio for the HUES3 HB9 reporter line; Susan Brenner-Morton and Thomas M. Jessell for graciously providing ISL1, HB9, RALDH2, and FOXP1 antibodies and motor neuron expertise; Lee Rubin for the human Smo agonist; David J. Kalher and Mathew Darwin-Zimmer (NYSCF) for help with FACS; R.M. Myers and F. Pauli, for performing RNA sequencing; and OB/GYN staff and the anonymous donors for tissue samples. We benefited from many helpful discussions with members of the Project A.L.S.; Wichterle, Henderson, and Eggan laboratories; and unwavering support from Valerie and Meredith Estess (Project A.L.S.).

*M.W.A. and G.F.C. contributed equally to this work.

The authors declare no competing financial interests.

Correspondence should be addressed to Hynek Wichterle, Columbia University, College of Physicians and Surgeons, PS14-401630 W. 168th Street. New York, NY 10032. E-mail: hw350@columbia.edu.

M.W. Amoroso's present address: Department of Molecular and Cellular Biology, Harvard University, Cambridge, MA 02138 .

DOI:10.1523/JNEUROSCI.0906-12.2013

Copyright $\odot 2013$ the authors $\quad 0270-6474 / 13 / 330574-13 \$ 15.00 / 0$ ment therapies for neurological diseases and injuries. However, if stem cell-derived populations are to become usable in large-scale in vitro studies, robust methods for their production need to be optimized for high yield and, crucially, for generation of cell types with molecular and functional characteristics matching those of in vivo cells.

While all spinal motor neurons innervate skeletal muscles, different subpopulations vary widely in their functional properties and in their resistance to disease. For example, motor neurons that innervate limb muscles selectively express genes such as FOXP1 that determine their identity (Dasen et al., 2008; Rousso et al., 2008) and are among the earliest affected in many patients with amyotrophic lateral sclerosis (ALS) (Kanning et al., 2010). Our insights into motor neuron diversity have so far been primarily based on mouse genetic studies in vivo (Dasen et al., 2009). The recent advent of induced pluripotent stem cell (iPSC) technology combined with directed differentiation of pluripotent stem cells to motor neurons (Takahashi et al., 2007; Dimos et al., 2008; Ebert et al., 2009) opened the way to modeling motor neuron degenerative diseases and to developing therapeutic strategies in vitro (Dimos et al., 2008; Ebert et al., 2009; Hu and Zhang, 2009). However, the subtype identity of motor neurons produced by current protocols remains poorly defined, making functional studies and disease modeling difficult to interpret.

Here, we first characterized and validated a set of established markers of motor neuron diversity in the embryonic human spinal cord. Next, by building on earlier reports (Li et al., 2005, 2008; 
Table 1. Primary antibodies

\begin{tabular}{llll}
\hline & Dilution & Supplier & Catalog no. \\
\hline Chicken anti-GFP & $1: 1000$ & Invitrogen & A10262 \\
Rabbit anti-GFP & $1: 5000$ & Abcam & Ab290 \\
Mouse anti-HB9 & $1: 50 / 1: 100$ & DSHB & $815 . c 10-5 / 815 . c 10-c$ \\
Guinea pig anti-HB9 & $1: 40,000$ & Thomas Jessell/Susan Morton & Columbia University \#1633 \\
& & & Human Hb9 n-TERM: NH2 \\
& & & MEKSKNFRIDALLAVDPRAAS(C) COOH \\
Guinea pig anti-Islet 1 (ISL1) & $1: 20,000$ & Thomas Jessell/Susan Morton & Columbia University \# 1278 \\
Mouse anti-Islet 1 (ISL1) & $1: 100$ & DSHB & $39.4 D 5$ \\
Mouse-anti $\beta$-III tubulin (TUJ1) & $1: 2000$ & Abcam & Ab14545 \\
Guinea pig anti-FOXP1 & $1: 40,000$ & Thomas Jessell/Susan Morton & Columbia University \# 1636 ENSIPLYTTASMGNPT(C) \\
Rabbit anti-FOXP1 & $1: 20,000$ & Abcam & Ab16645 \\
Mouse anti-LHX3 & $1: 200$ & DSHB & 4E12 \\
mouse anti-NF-H (nonphosphorylated; SMI-32) & $1: 5000$ & Santa Cruz Technology & SC-58554 \\
Rabbit anti-RALDH2 & $1: 20,000$ & Thomas Jessell/Susan Morton & Columbia University \# 1676 \\
BRN3A & $1: 1000$ & Santa Cruz Technology & sC-8429 \\
\hline
\end{tabular}

Lee et al., 2007b; Chambers et al., 2009; Patani et al., 2011), we developed an accelerated and highly efficient protocol for directed differentiation of human embryonic stem cell (hESC) and iPSCs into motor neurons. Although the differentiation is accelerated, motor neurons generated under this protocol express canonical markers matching those in embryonic human spinal cord in vivo, are responsive to glutamate agonists, and show an ability to project axons when grafted into the developing chicken spinal cord. Most importantly, this method results in a novel preferential generation of motor neurons expressing markers of limb muscle-innervating lateral motor column (LMC) neurons. Thus, motor neurons produced under the new protocol might become an important and versatile tool to study subtype-specific differences in motor neuron function and susceptibility to degeneration in motor diseases such as ALS.

\section{Materials and Methods}

All cell cultures were maintained at $37^{\circ} \mathrm{C}, 5 \% \mathrm{CO}_{2}$. hES and iPS cells [HUES3 (control), male; H9 (control), female; HS001 (ALS-SOD1 N139K), male; LWM002 (ALS-SOD1 A4V), female; MBN007 (ALSSOD1 A4V), female; TM008 (ALS-SOD1 A4V), female; DCM009 (ALSSOD1 V148G), male; 10013.13 (control), male)] were maintained on gelatinized tissue-culture plastic on a monolayer of irradiated CF-1 mouse embryonic fibroblasts (GlobalStem), in hESC media, consisting of DMEM: nutrient mixture F-12 (DMEM/F:12; Invitrogen) with 20\% Knockout Serum Replacer (Invitrogen), $110 \mu \mathrm{M} \beta$-mercaptoethanol (BME; Sigma), L-glutamine and nonessential amino acids (NEAA; Invitrogen), and $20 \mathrm{ng} / \mathrm{ml}$ basic fibroblast growth factor (bFGF; Invitrogen) (Cowan et al., 2004). Media was changed every $24 \mathrm{~h}$ and lines were passaged with dispase (Invitrogen, $1 \mathrm{mg} / \mathrm{ml}$ in hESC media for 15-30 min at $37^{\circ} \mathrm{C}$ ).

To generate motor neurons, undifferentiated hESCs were passaged using dispase ( $1 \mathrm{mg} / \mathrm{ml})$ and triturated into small, 50- to 100-cell clumps and placed into ultralow adherent culture dishes (Corning). For the first $3 \mathrm{~d}$, cells were kept in suspension in hESC medium, supplemented with $10 \mu \mathrm{M}$ Rho-associated kinase inhibitor Y27632 (Ascent Scientific) to enhance single cell survival (Watanabe et al., 2007), $20 \mathrm{ng} / \mathrm{ml} \mathrm{bFGF} \mathrm{(Invit-}$ rogen) to enhance growth, and $10 \mu \mathrm{M}$ SB435142 (SB; Sigma) and $0.2 \mu \mathrm{M}$ LDN193189 (LDN; Stemgent) for neuralization. At day 3, embryoid bodies (EBs) were switched to neural induction medium (DMEM/F:12 with L-glutamine; NEAA; penicillin/streptomycin; heparin, $2 \mu \mathrm{g} / \mathrm{ml}$; N2 supplement; Invitrogen). At day 5, all-trans retinoic acid (RA; 0.1 or 1 $\mu \mathrm{M}$; Sigma), ascorbic acid (0.4 $\mu \mathrm{g} / \mathrm{ml}$; Sigma), and brain-derived neurotrophic factor $(10 \mathrm{ng} / \mathrm{ml}$; R\&D) were added. Dual ALK inhibition (SB + LDN) was pursued until day 7 . Hedgehog signaling was initiated on day 7 by application of C25II modified SHH (R\&D), at the standard concentration of $200 \mathrm{ng} / \mathrm{ml}$; a human Smo agonist (HAG, $1 \mu \mathrm{M}$; gift from Lee Rubin; Dimos et al., 2008; Boulting et al., 2011); mouse Smo agonist
1.3 (SAG; $1 \mu \mathrm{M}$; Frank-Kamenetsky et al., 2002; Wichterle et al., 2002; Wada et al., 2009; Boulting et al., 2011); or purmorphamine (PUR, $1 \mu \mathrm{M}$; Stemgent; Sinha and Chen, 2006; Li et al., 2008). At day 17, basal medium was changed to Neurobasal (Invitrogen), containing all previous factors and with the addition of $10 \mathrm{ng} / \mathrm{ml}$ each of insulin-like growth factor 1 (IGF-1), glial cell line-derived neurotrophic factor (GDNF), and ciliary neurotrophic factor (CNTF) (R\&D), plus B27 (Invitrogen). At day 20 or 30 , EBs were dissociated with $0.05 \%$ trypsin (Invitrogen) and plated onto poly-lysine/laminin-coated 8-well chamber slides (BD Biosciences) at $0.2-0.5 .10^{6}$ cells/well and/or $15 \mathrm{~mm}$ coverslips at $0.5 .10^{6}$. Plated neurons were cultured in the same medium with the addition of $25 \mu \mathrm{M}$ BME and $25 \mu \mathrm{M}$ glutamic acid (Sigma) and fixed $1 \mathrm{~d}$ later.

For immunocytochemistry assays, cultures were fixed for $30 \mathrm{~min}$ with $4 \%$ paraformaldehyde (PFA) in $\mathrm{PBS}$ at $4^{\circ} \mathrm{C}$, washed three times for $5 \mathrm{~min}$ in PBS, quenched, and permeabilized in wash buffer (PBS, $0.1 \%$ Triton $\mathrm{X}-100)$ plus $50 \mathrm{~mm}$ glycine for $15 \mathrm{~min}$. For the EB outgrowth RALDH2 staining, samples were fixed for $10 \mathrm{~min}$ at room temperature with $4 \%$ $\mathrm{PFA} / 10 \%$ sucrose prewarmed to $37^{\circ} \mathrm{C}$. Samples were blocked with wash buffer plus $10 \%$ normal donkey serum for $1 \mathrm{~h}$ and incubated with primary antibody (Table 1) overnight. Cells were then washed, incubated with DyLight coupled donkey primary anti-secondary antibodies (Jackson ImmunoResearch, 1:1000). Finally, cells were washed and counterstained with DAPI (Invitrogen).

Quantitative image analysis of differentiated neuronal cultures was performed using the Multi-Wavelength Cell Scoring module in MetaMorph software (Molecular Devices). Briefly, EBs were dissociated enzymatically and plated in the presence of neurotrophic factors at densities for which cell overlap was minimal. Following immunostaining, images of at least nine randomly selected fields ( $>15,000$ cells in total) for each condition were captured using a preprogrammed automated microscope stage. Images were analyzed using the Multi-Wavelength Cell Scoring module of the MetaMorph software, using parameters predefined to count only unambiguous bright labeling for each antigen. Intensity thresholds were set while blinded to sample identity to selectively identify positive cells that displayed unambiguous signal intensity above local background. These parameters were used on all samples in a given experiment, and only minimally adjusted for different staining batches as necessary. Script and Parameter files are available upon request (typically, a cell was $\sim 5000$ gray levels above background to be called positive for any nuclear marker and was $\sim 10,000$ for cytoplasmic markers). A minimum of 15,000 cells per sample was analyzed. All samples were imaged using $10 \times$ or $20 \times$ objectives on a Zeiss AxioObserver with a Coolsnap $\mathrm{HQ}_{2}$ camera (Photometrics). Some images were acquired using a structured illumination technique using an Apotome module (Zeiss) to achieve $1.9 \mu \mathrm{m}$ optical sections to ensure colocalization of labeling. For the figures, the brightness and contrast of each channel of an image were adjusted in an appropriate manner to improve clarity.

For $\mathrm{Ca}^{2+}$ imaging experiments using the $\mathrm{Hb} b$ ::GFP reporter, stem cells were differentiated under the motor neuron differentiation protocol 
described above, dissociated at day 21 or day 31, and FACS sorted based on green fluorescent protein (GFP) intensity with a five laser ARIA-IIu ROU Cell Sorter configured with a $100 \mu \mathrm{m}$ ceramic nozzle and operating at $20 \mathrm{psi}$ (BD BioSciences). The H9 assays were comprised of mixed neuronal cultures, for which a parallel coverslip was stained and quantified to have $53 \% \mathrm{HB} / \mathrm{ISL}_{1}{ }^{+}$motor neurons. All cultures were plated onto $15-25 \mathrm{~mm}$ diameter coverslips at a density of 100,000-150,000 cells per coverslip in day $17+$ Neurobasal media with factors described above, with the addition of $0.5 \mu \mathrm{M} \mathrm{EdU}$, and matured $6 \mathrm{~d}$ before $\mathrm{Ca}^{2+}$ imaging. Cells were loaded with $3 \mu \mathrm{M}$ Fluo-4 AM (Invitrogen) dissolved in $0.2 \%$ dimethylsulfoxide/0.04\% pluronic acid (Sigma) in HEPES-buffered physiological salt solution (PSS) for $1 \mathrm{~h}$ at room temperature. PSS contained the following (in mM): $145 \mathrm{NaCl}, 5 \mathrm{KCl}, 10 \mathrm{HEPES}, 2 \mathrm{CaCl}_{2}, 2$ $\mathrm{MgCl}_{2}$, and 5.5 glucose ( $\mathrm{pH}$ 7.4). Cultures were continuously superfused with PSS at a rate of $\sim 0.5 \mathrm{ml} / \mathrm{min}$. The cultures were imaged using a $10 \times$ objective on an inverted epifluorescent Zeiss AxioObserver microscope, equipped with a Coolsnap $\mathrm{HQ}_{2}$ camera (Photometrics). For imaging spontaneous $\mathrm{Ca}^{2+}$ transients, single sets of 200-300 images were acquired at a rate of $\sim 2 \mathrm{~Hz}$ from each coverslip. For the kainate (KA) experiments, 36 images were acquired at a rate of $0.033 \mathrm{~Hz}$ and the superfusing PSS was replaced with PSS-containing KA $(100 \mu \mathrm{M})$ for $60 \mathrm{~s}$. Image analysis was performed using ImageJ (http://rsb.info.nih.gov/ij/) or AxioVision 4.7 (Zeiss). $\mathrm{Ca}^{2+}$ transients were determined from regions of interest encompassing the soma of individual cells. A minimum of two cultures obtained from a single differentiation of each cell line and each time point were used for the $\mathrm{KA}$ and all $\mathrm{Ca}^{2+}$ imaging experiments.

For whole-cell patch-clamp recordings, $\mathrm{S}+\mathrm{P}$ differentiated HUES3 Hb9::GFP cells were plated on polyornithine/laminin-coated $25 \mathrm{~mm}$ diameter coverglass at density of 50,000 per coverslip and cultured for $7 \mathrm{~d}$ in the presence of $0.5 \mu \mathrm{M}$ EdU before recording (i.e., $21+7$ days in vitro; DIV). Current-clamp recordings were performed using an Axopatch 2B amplifier. Data were digitized using a Digidata 1322A digital to analog converter and were recorded at a $10 \mathrm{kHz}$ sample rate using pClamp 10 software (all equipment from Molecular Devices). Patch pipettes were fabricated using a P-97 pipette puller (Sutter Instruments). The external recording solution contained the following (in $\mathrm{mM}$ ): $145 \mathrm{NaCl}, 5 \mathrm{KCl}, 10$ HEPES, 10 glucose, $2 \mathrm{CaCl}_{2}$, and $2 \mathrm{MgCl}_{2}$. The $\mathrm{pH}$ was adjusted to 7.3 using $\mathrm{NaOH}$ and the osmolality adjusted to $325 \mathrm{mOsm}$ with sucrose. The pipette solution contained the following (in $\mathrm{mM}$ ): $130 \mathrm{CH}_{3} \mathrm{KO}_{3} \mathrm{~S}, 10$ $\mathrm{CH}_{3} \mathrm{NaO}_{3} \mathrm{~S}, 1 \mathrm{CaCl}_{2}, 10$ EGTA, 10 HEPES, $5 \mathrm{MgATP}$, and $0.5 \mathrm{Na}_{2} \mathrm{GTP}$ ( $\mathrm{pH} 7.3,305 \mathrm{mOsm})$. Experiments were performed at room temperature $\left(21-23^{\circ} \mathrm{C}\right)$. During recordings, current was injected to hold the cells at $\sim-60 \mathrm{mV}$. Action potentials (APs) were evoked using incrementally increasing current steps $1 \mathrm{~s}$ in duration. The maximum amplitude of the current step (20-50 pA) and the size of the increment were calculated based on the input resistance of the cell.

To perform xenotransplantations day 21 EBs from HUES3 Hb9::GFP under ventralization with SAG + PUR were collected and placed into L-15 media (Invitrogen) containing penicillin/streptomycin (Invitrogen). Transplantation was performed as previously described (Wichterle et al., 2002). Briefly, after a small suction lesion at the prospective intraspinal site was created in a chick embryo at stage 15-18 at somites 15-20, lightly triturated EBs were loaded into a handheld micro-injector. The EBs was placed into the lesion. After $48 \mathrm{~h}$, the chicks were sacrificed, fixed with $4 \%$ PFA for $2 \mathrm{~h}$ at $4^{\circ} \mathrm{C}$, and neurite outgrowth and cell body placement was accessed by cutting $200 \mu \mathrm{m}$ vibratome sections $(n=2)$ or by cutting $30 \mu \mathrm{m}$ sections along the spinal cord $(n=5)$.

Human embryonic spinal cords were collected in accordance with the national guidelines of the United States (National Institutes of Health, U.S. Food and Drug Administration) and the State of New York and under Columbia University institutionally approved ethical guidelines relating to anonymous tissue. The material was obtained after elective abortions, and was classified on the basis of external morphology according to the Carnegie stages. Gestational age was determined by last menstrual period of the patient or by ultrasound, if the ultrasound estimate differed by $>1$ week as indicated by the obstetrician. The spinal cord was removed as intact as possible before fixation with fresh, cold $4 \%$ PFA for $1.5 \mathrm{~h}$ on ice. Postfixation, the cord was measured and cut into three anatomical sections to accommodate embedding in OCT Compound (Tissue-Tek) and stored
Table 2. qPCR primer sequences

\begin{tabular}{lll}
\hline Primers & Forward & Reverse \\
\hline RALDH2 & TTTTGCTGATGCTGACTTGG & GCAGCACTGACCTTGATTGA \\
FOXP1 & TGACCTTTTGAGGTGACTATAACTG & TGGCTGAACCGTTACTTTTTG \\
LHX3 & GTTCAGGAGGGGCAGGAC & CCCAAGCTCCCGTAGAGG \\
CHT1 & AAGCCATCATAGTTGGTGGCCGA & CCAAGCTAGGCCATAACCTGGTAC \\
HOXA5 & CAGCACCCACATCA & CGGAGAGGCAAAGA \\
HOXC6 & CCAGGACCAGAAAGCCAGTA & GTTAGGTAGCGATTGAAGTGAAA \\
HOXC8 & CTTCGCTGTTTGATTTCTATTCTG & TACGCTGGAGGTTCTTTCTTT \\
HOXD9 & TCGCTGAAGGAGGAGGAGA & CAAACACCCACAAAGGAAAC \\
\hline
\end{tabular}

STD qPCR amplification: $95^{\circ}-30^{\prime \prime}, 55^{\circ}-60^{\prime \prime}, 72^{\circ}-45^{\prime \prime}$.

at $-80^{\circ} \mathrm{C}$ before cutting on a microtome. Sections $(12 \mu \mathrm{m})$ were cut along the full length of the cord, taking care to have all three sections on each slide in seven independent sections. This allowed for full analysis and internal staining controls since each slide had cervical, brachial, thoracic, and lumbar sections that clearly showed staining within the various motor columns present at different rostrocaudal levels of the spinal cord.

cDNA was obtained from 50,000 FACS-purified motor neurons from either day $21 \mathrm{~S}+\mathrm{P}$ (methods described above), or from RA/SHH motor neurons at day 31. cDNA preparation was performed using commercially available kits following the manufacturer's instructions: RNA isolation (Trizol LS; Invitrogen) and cDNA by Brilliant II SYBR green (Stratagene) without amplification. All samples were processed in parallel on the same quantitative PCR (qPCR) plate (Table 2).

For paired-end RNA-Seq experiments, 400 ng of total RNA was prepared after FACS purification of 500,000 $\mathrm{GFP}^{+}$or GFP $^{-}$cells. The RNA samples were then amplified using a NuGEN RNA kit for genomic sample amplification, and sequenced to a depth of $21(\mathrm{~S}+\mathrm{P})$ and $35(\mathrm{SHH})$ million paired-end reads on an Illumina HiSeq instrument at the HudsonAlpha Institute of Biotechnology. The reads were aligned to the reference transcriptome as well as a library of exon junctions using Bowtie (Version 1) (Langmead et al., 2009). Data were analyzed using Expression Plot (Friedman and Maniatis, 2011) using a $p$ value of 0.001 and a twofold change threshold. Gene ontology was performed using DAVID (Huang da et al., 2009a, b) with enrichment sets from Expression Plot. The RNA-seq data are available in the Gene Expression Omnibus database (http://www.ncbi.nlm.nih.gov/geo/) under the accession number GSE41795.

All quantitative data were analyzed using Sigma Plot 11 or Microsoft Excel. Sample groups were subject to Student's $t$-test or where appropriate a one-way ANOVA with Holm-Sidak post hoc pairwise comparisons was performed. All experimental data passed an equal variance and normality test (Shapiro-Wilk).

\section{Results}

\section{Accelerated motor neuron differentiation under optimized neuralization and ventralization conditions}

Specification of motor neuron identity depends on three critical steps: neuralization, caudalization, and ventralization of precursors (Wichterle et al., 2002). Previous reports have shown that dual inhibition of SMAD signaling by a combination of recombinant noggin protein, or a small-molecule substitute, LDN193189, and SB431542 neuralizes hESCs with very high efficiency (Chambers et al., 2009; Boulting et al., 2011; Kriks et al., 2011), bypassing the need for manual rosette picking. Thus, we sought to determine the effects of optimal caudalization and ventralization on motor neuron yields following neuralization. To assess motor neuron numbers we relied initially on the HUES3 Hb9::GFP reporter line (Di Giorgio et al., 2008), which contains a transgene-expressing GFP under the control of the motor neuron-specific $\mathrm{Hb} 9$ promoter.

Using a standard RA/SHH protocol involving RA and a modified sonic hedgehog (SHH-C25II) protein as a benchmark for differentiation of neuralized hESCs into motor neurons, we systematically compared the ventralizing activity of three Smooth- 
A

D
B

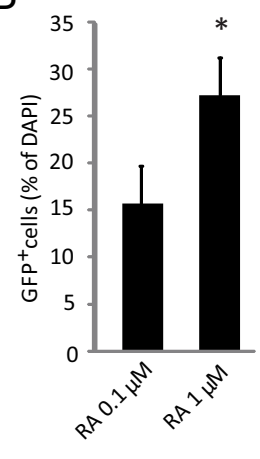

C

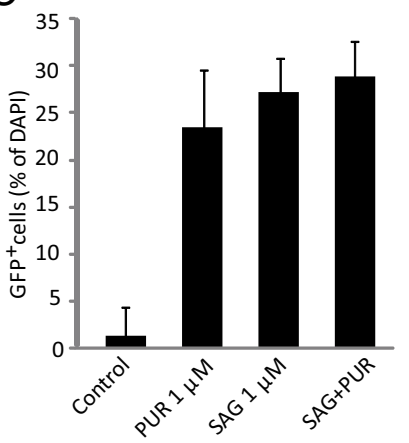

hES/iPS Embryoid Bodies

\begin{tabular}{llllll} 
Day 0 & Day 5 & Day 7 & Day 17 & Day 21 \\
\hline & RA & & NTFs & Day 31 \\
\cline { 2 - 5 } $\begin{array}{c}\text { Y27632 } \\
\text { bFGF }\end{array}$ & & Condition 1: S+P & &
\end{tabular}

SB435142 Condition 2: SHH

LDN193189

$\mathrm{E}$
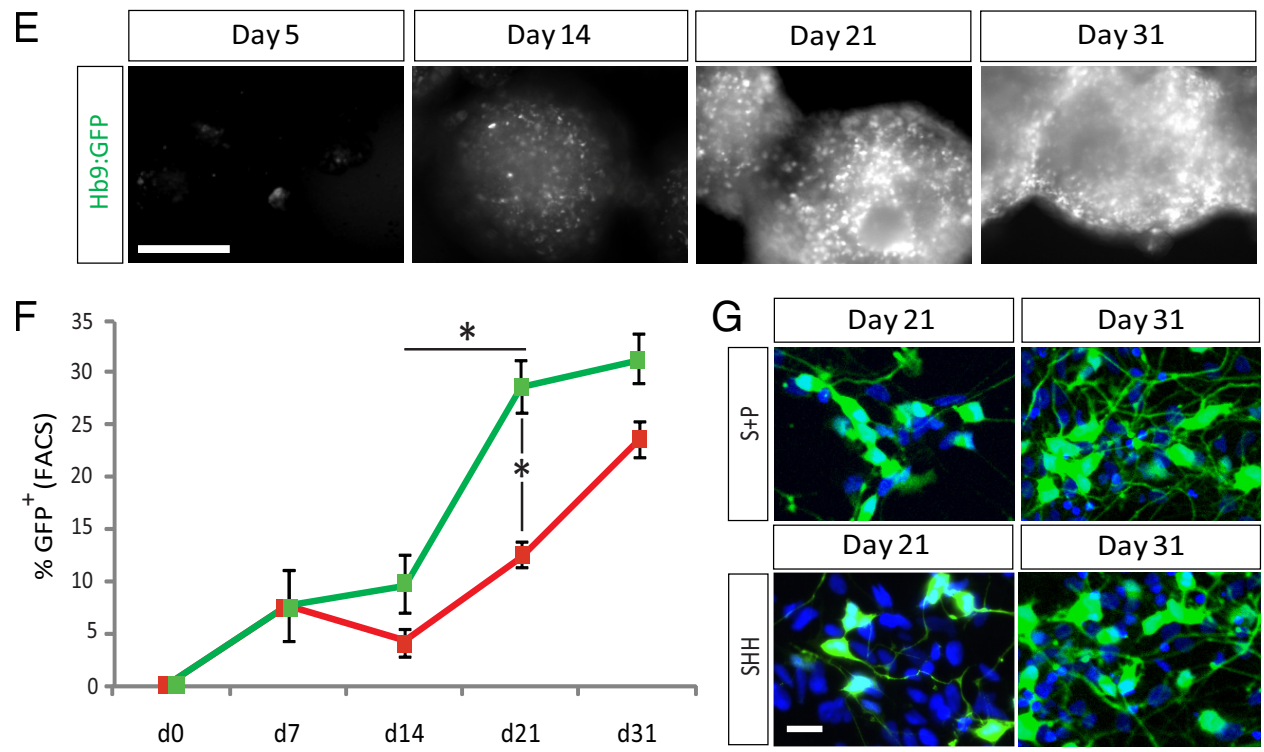

Figure 1. Accelerated induction of motor neuron-specific Hb9::GFP expression under optimized $S+P$ conditions. $A$, Using the Hb9::GFP reporter line, ventralization was assessed from the proportion of the total (DAPI stained) cells that were GFP ${ }^{+}$. The standard $30 \mathrm{~d}$ motor neuron differentiation protocol using $0.1 \mu \mathrm{m}$ RA was followed. Cells were dissociated and fixed $1 \mathrm{~d}$ later (day 31). Testing known Smoothened agonists against the recombinant human protein showed that several agonists, $\mathrm{SAG}(1 \mu \mathrm{M})$ and PUR (1 $\mu \mathrm{M})$, outperformed the recombinant SHH (200 ng/ml) or HAG $(1 \mu \mathrm{M})$, although not significantly (one-way ANOVA). $\boldsymbol{B}$, We tested a 10-fold increase in RA concentration, in combination with SAG $1 \mu \mathrm{M}$, and found that $1 \mu \mathrm{m}$ RA was significantly better. ( $n=3$, $p=0.013$ ). C, After establishing that there were more motor neurons by day 31 with a high RA concentration (1 $\mu \mathrm{m}$ ), we again tested SAG, PUR, and the combination of SAG + PUR (not significant, one-way ANOVA). D, Differentiation schematic showing timing of neuralization from day 0 to 7 with SB431542 at $10 \mu \mathrm{m}$ and LDN193189 at $0.2 \mu \mathrm{M}$, caudalization with RA $1 \mu \mathrm{m}$ from day 5 onward, and ventralization from day 7 onward with either SAG $1 \mu \mathrm{M}+$ PUR $1 \mu \mathrm{M}$ (condition 1) or SHH $200 \mathrm{ng} / \mathrm{ml}$ (condition 2). At day 17 additional neurotrophic support was added with GDNF $10 \mathrm{ng} / \mathrm{ml}$, CNTF $10 \mathrm{ng} / \mathrm{ml}$, and IGF-1 $10 \mathrm{ng} / \mathrm{ml}$. $\boldsymbol{E}$, Endogenous live GFP expression in embryoid bodies during differentiation days 5, 14, 21, and 31. F, Differentiation efficiency was quantified using FACS analysis. Cells were dissociated and analyzed at day $0,7,14,21$, and 31. FACS analysis of the $S+P$ (green line) and the SHH (red line) culture at the time points specified ( $n=3-4$ each for $S+P$, $n=2-4$ each for SHH). Asterisks: Day 21 comparison of $S+P$ to $S H H, p=0.001$. Day 21 to day 14 for $S+P, p=0.003$. G, Representative images showing motor neurons (GFP) and DAPI immunocytochemistry at day 21 and 31 for both the $S+P$ and SHH method. Scale bars: (for $E) 100 \mu \mathrm{m}$; (for $G) 10 \mu \mathrm{m}$. Data presented as mean \pm SEM.

ened (Smo) agonists (Frank-Kamenetsky et al., 2002; Li et al., 2008; Wada et al., 2009; Boulting et al., 2011). The abundance of motor neurons was estimated on day 31, following dissociation and plating on day 30 (see Materials and Methods), by counting the percentage of all cells that expressed GFP (Fig. 1A, $n=3$ biological replicates for all experiments unless specified). Very few GFP-positive cells were observed in the absence of exogenous SHH agonists. Recombinant SHH and human-specific Smo agonist (HAG) each gave rise to $<10 \% \mathrm{GFP}^{+}$cells, as previously reported (Lee et al., 2007b; Di Giorgio et al., 2008; Boulting et al., 2011). In contrast, the Smo agonist SAG alone gave rise to $16 \pm$ $4 \% \mathrm{GFP}^{+}$cells and PUR alone induced $22 \pm 6 \%$. To optimize caudalization of the cultures, we then tested a higher concentration of RA $(1 \mu \mathrm{M} ;$ Fig. $1 B)$. This led to an additional increase in the abundance of GFP ${ }^{+}$cells: $27 \pm 4 \%$ of cells expressed GFP at day 31 when ventralized with SAG $(1 \mu \mathrm{M})$ alone or $24 \pm 6 \%$ with PUR $(1 \mu \mathrm{M})$ alone (Fig. 1C). When cultures were exposed to a combination of $1 \mu \mathrm{M}$ SAG and $1 \mu \mathrm{M}$ PUR $29 \pm 4 \%$ cells were $\mathrm{GFP}^{+}$ 
(Fig. 1C) on day 31. Systematic titration of PUR and SAG alone or in combination did not further increase motor neuron abundance on day 21 , indicating that the combination of $1 \mu \mathrm{M}$ SAG and $1 \mu \mathrm{M}$ PUR is close to optimal (data not shown). Thus, for subsequent experiments we treated cells with a combination of $\mathrm{RA}, \mathrm{SAG}$, and PUR (we refer to this as the " $\mathrm{S}+\mathrm{P}$ " method) or RA and $\mathrm{SHH}$ ("SHH") as a control.

We noticed that with the S + P method GFP-positive cells appeared earlier in culture than with SHH. Using the Hb9::GFP reporter line we therefore examined the time course of motor neuron generation from neuralized precursors using either $\mathrm{SHH}-$ or S + P-mediated ventralization (Fig. 1D). By day 21 under S + $\mathrm{P}$ conditions, $\mathrm{GFP}^{+}$cells had already reached a plateau at $29 \pm$ $3 \%$ of all cells (Fig. $1 E, F$ ), a value significantly higher than with $\mathrm{SHH}\left(12 \pm 1 \% \mathrm{GFP}^{+} ; n=3-4, p=0.001\right)$ at the same time (Fig. $1 F, G)$. These data indicate that treatment of neural precursors with a combination of $S+P$ accelerates motor neuron differentiation, possibly through enhanced and more uniform ventralization.

To ensure that the $\mathrm{S}+\mathrm{P}$ condition did not induce ectopic GFP reporter expression in non-motor neurons, we examined the expression of endogenous glial, neural crest, panneuronal and motor neuron-specific markers (Li et al., 2005; Hu and Zhang, 2009; Wada et al., 2009; Hester et al., 2011). At day 21 there were no GFAP- or SOX10-positive glial cells (data not shown). Less than $1 \%$ of all cells expressed BRN3A, a marker of neural crest-derived sensory neurons and spinal interneurons (Lee et al., 2007a) and none of the BRN3A ${ }^{+}$cells costained with GFP (Fig. $2 A$ ). A majority of plated cells $\left(83 \pm 1 \%\right.$ of DAPI $\left.{ }^{+}, n=2\right)$ expressed the panneuronal marker $\beta$-III-tubulin (TUJ1), consistent with efficient neuralization (Fig. $2 B$ ), and essentially all GFP ${ }^{+}$cells $(98 \pm$ $0 \% ; n=2$ ) exhibited neuronal morphology and were positive for TUJ1 (Fig. 2B). Immunostaining with SMI-32 antibody recognizing a mature neuronal marker neurofilament heavy chain labeled most GFP-expressing cells in $\mathrm{S}+\mathrm{P}$ cultures (Fig. 2C). qPCR analysis of RNA isolated from FACS-sorted GFP-positive cells from both S + P and SHH cultures revealed 700- to 800-fold induction of high-affinity choline transporter 1 (CHT1 or SLC5A7), a marker of cholinergic neurons, when compared with RNA isolated from undifferentiated ESCs. Thus, optimized differentiation of hESCs results in efficient and accelerated production of cells expressing markers of mature spinal motor neuron identity.

\section{Efficient motor neuron differentiation revealed by combined HB9 and ISL1 immunostaining}

To determine whether the accelerated differentiation was also applicable to other cell lines that do not carry a fluorescent motor neuron reporter we established parameters for scoring motor neuron induction immunocytochemically, using antibodies to the motor neuron markers HB9 and ISL1. Although nearly all $\mathrm{GFP}^{+}$cells $(83 \pm 4 \%)$ expressed either HB9 and/or ISL1 (Fig. $2 D, E)$, many did so in a nonoverlapping manner. Indeed, of all GFP-expressing cells $16 \pm 5 \%$ were HB9 positive, $30 \pm 6 \%$ were ISL1 positive, and $37 \pm 2 \%$ were double positive (Fig. $2 E$ ). Since previous studies have often considered Hb9 and ISL1 to be overlapping markers for motor neurons, we asked whether this heterogeneity had an in vivo counterpart. In the developing mouse spinal expression of $H b 9$ ::GFP the reporter is maintained in all postmitotic motor neurons (Arber et al., 1999; Wichterle et al., 2002; Thaler et al., 2004), whereas HB9 and ISL1 transcription factors are selectively downregulated in medial and lateral divisions of the $\mathrm{LMC}\left(\mathrm{LMC}_{\mathrm{m}}\right.$ and $\left.\mathrm{LMC}_{1}\right)$, respectively (Thaler et al.,
2004). Therefore, the observed nonoverlapping pattern of HB9 and ISL1 expression may reflect acquisition of distinct motor neuron subtype identities by in vitro-generated motor neurons.

To establish whether a similarly complex pattern of ISL1 and HB9 expression extends to human cells in vivo, we examined the expression of these markers in human embryonic spinal cord at the seventh week of development (Carnegie stage 19-22), a stage analogous to mouse E13-E14 when motor columns are anatomically well demarcated (Fig. $2 F-H$ ). At brachial and lumbar limb levels, motor columns corresponding to the $\mathrm{LMC}_{\mathrm{m}}$ and $\mathrm{LMC}_{\mathrm{l}}$, and to the median motor column (MMC), were apparent. Consistent with the pattern of expression in chick and mouse, the MMC expressed both HB9 and ISL1, the $\mathrm{LMC}_{1}$ was ISL1 ${ }^{-}$/ $\mathrm{HB}^{+}{ }^{+}$, and many $\mathrm{LMC}_{\mathrm{m}}$ neurons were $\mathrm{ISL}^{+} / \mathrm{HB}^{-}{ }^{-}$. Interestingly, a group of motor neurons located within the $\mathrm{LMC}_{\mathrm{m}}$ division were double positive for ISL1 and HB9, an expression pattern not reported in chick and mouse spinal cord (Fig. $2 G$ and data not shown). At thoracic levels, putative MMC and hypaxial motor column (HMC) neurons coexpressed HB9 and ISL1, with a tendency for higher HB9 expression in the MMC and higher ISL1 expression in HMC neurons (Fig. $2 H$ ). To estimate the relative abundance of cells expressing different combinations of HB9 and ISL1, motor neurons with bright HB9 or ISL1 labeling were evaluated in multiple brachial and thoracic segments. Overall, $44 \%$ of all motor neurons expressed ISL1 alone, $31 \%$ expressed HB9 alone, and 25\% expressed both HB9 and ISL1 (Fig. $2 \mathrm{~F}-\mathrm{H}$ ). This distribution was remarkably similar to the distribution of single- and double-positive motor neuron populations observed in vitro (Fig. $2 F$ ). Therefore, as in developing avian and rodent spinal cords, human motor neurons are characterized by variable patterns of HB9 and ISL1 expression.

Based on these observations we suggest that a combination of HB9 and ISL1 (referred to subsequently as "pan-MN") is the most accurate measure of total motor neuron yield when human cell lines lacking a GFP reporter are differentiated into motor neurons. However, since not all ISL1-positive cells in the developing spinal cord are motor neurons, we considered potential sources of error in this parameter. For the Hb9::GFP line, the pan-MN value was $42 \pm 1 \%$, which is indeed similar to the total percentage of GFP-expressing cells ( $31 \pm 2 \%$, Fig. $1 F)$. Although $>98 \%$ of all cells that express $\mathrm{HB} 9$ were $\mathrm{GFP}^{+}$, a smaller fraction, $71 \pm 5 \%$, of all ISL1 ${ }^{+}$cells coexpress GFP. The remaining $29 \%$ that did not express GFP may correspond to non-motor neurons, meaning that of the pan-MN value $(42 \%)$, the fraction that is ISL $1+$ only may be overestimated by $9 \%$. However, this potential error is minor compared with that induced by counting HB9- or ISL1-labeled cells only. Although frequently used, such approaches potentially underestimate total motor neuron abundance by $\sim 20 \%$. Therefore, pan-MN staining provides a more reliable estimate of motor neuron number.

Using this criterion, we asked whether the S + P method, which had been optimized using a single hESC line, was applicable to other human stem cell lines. The H9 hESC line was recently reported to show stronger proneural characteristics than the HUES3 Hb9::GFP reporter line (Bock et al., 2011). Using the accelerated protocol, $\mathrm{H} 9$ was indeed more efficient than HUES3 at producing motor neurons: a total of $51 \%$ of all cells expressed the pan-MN signature (Fig. 2I). We expanded our analysis to a set of six iPS cell lines generated from healthy patients and patients with ALS. We found that all the lines generated motor neurons under $\mathrm{S}+\mathrm{P}$ conditions with a similar efficiency to that of control hESCs by day 21 of culture $(27 \pm 1 \%$ pan-MNs, six lines each differentiated from two biological replicates; Fig. 2I). 
A

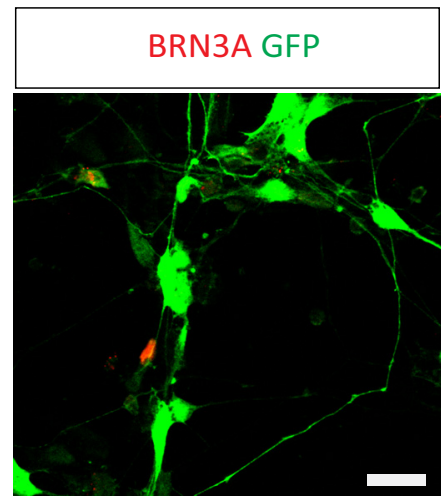

D

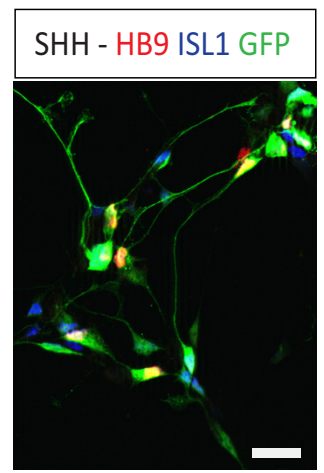

G

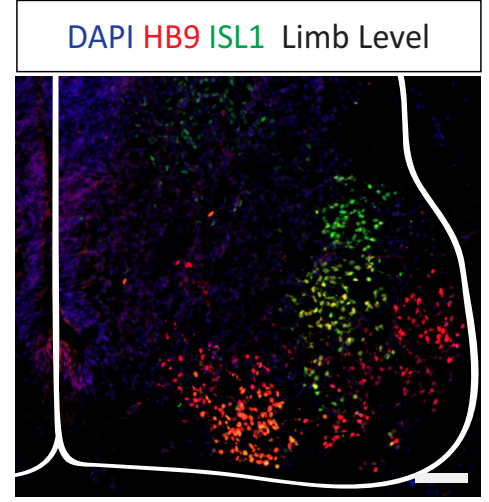

B
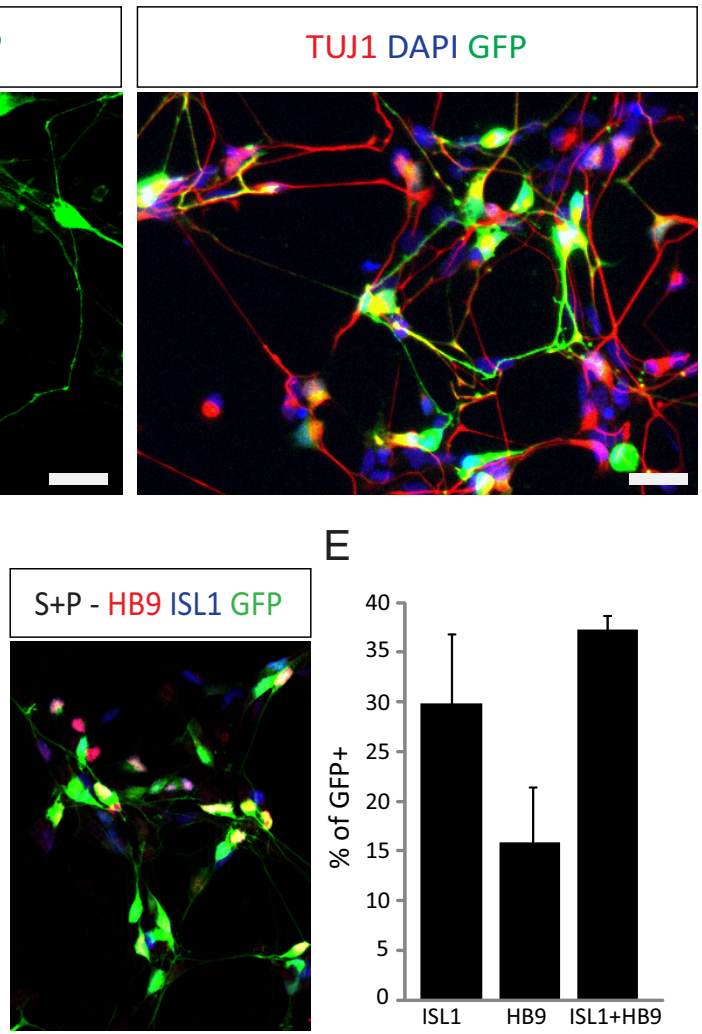

$\mathrm{H}$

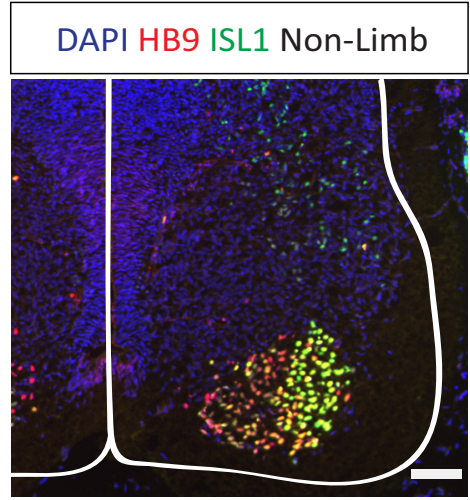

E

C

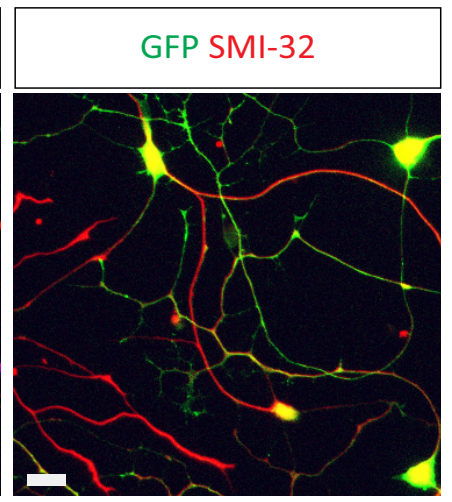

F

- ISL1

- HB9 + ISL1

- HB9
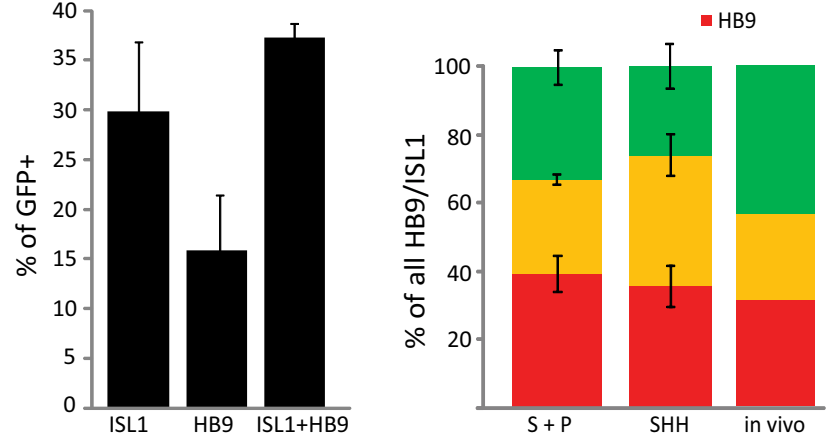

I

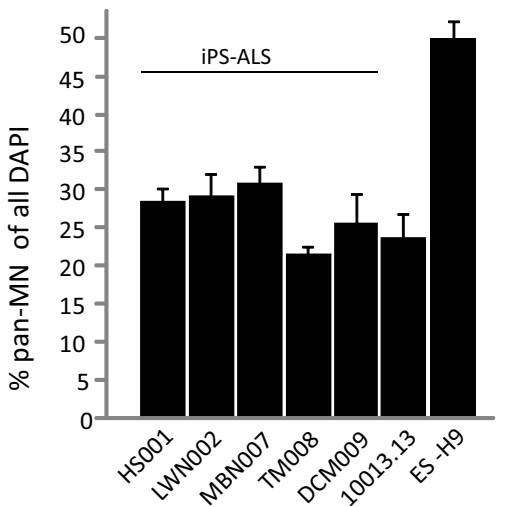

Figure 2. Molecular characterization of human motor neurons in vitro and in vivo. $A$, At day $21, S+P$-derived cultures showing BRN3A in red and GFP in green. $B, S+P$ cultures robustly expressed TUJ1 (TUJ1, red; GFP, green; DAPI, blue). C, Image of S + P-derived motor neurons stained for GFP and SMI-32 at $21+14 \mathrm{~d}$ in culture. D, Representative images of $S+P$ - and SHH-derived motor neurons (GFP) expressing HB9 and ISL1. E, Percentage of GFP ${ }^{+}$motor neurons that express ISL1 ${ }^{+}$only, HB9 ${ }^{+}$only, or ISL1 ${ }^{+}$and HB9 ${ }^{+}$concurrently. $F$, Quantification of HB9 and ISL1 expression in vitro using the accelerated S + P protocol (day 21) and the traditional protocol with SHH (day 31) and human in vivo. Values are shown as a percentage of all HB9/ISL1 cells for each of the mutually exclusive categories of $\mathrm{HB9}{ }^{+}$only, ISL1 ${ }^{+}$only, or HB9 and ISL1 coexpressed. G, Representative image of human spinal cords from the limb level for DAPI (blue), HB9 (red), and ISL1 (green). Colocalization of HB9 and ISL1 is shown in yellow. $\boldsymbol{H}$, Representative image of human spinal cords from the nonlimb level for DAPI (blue), HB9 (red), and ISL1 (green). Colocalization of HB9 and ISL1 is shown in yellow. I, Quantification of pan-MN (HB9 + ISL1) from seven additional stem cell lines ( $n=2$ biological replicates each except for H9, which is $n=3)$. $S c a l e$ bars: (for A-D) $15 \mu \mathrm{m}$; (for $\mathbf{G}, \boldsymbol{H}) 100 \mu \mathrm{m}$. All images are derived from the Hb9::GFP reporter line. Data presented as mean \pm SEM.

We conclude that the $S+P$ protocol provides a robust and general approach for the generation of motor neurons from human stem cell lines.

Genome-wide profiling of $S+P$ motor neurons by RNA sequencing

To further characterize stem cell-derived neurons in an unbiased manner, we performed whole-transcriptome sequencing of RNA (RNA-seq) from FACS-purified S + P-derived and SHH-derived motor neurons (Hb9::GFP reporter line) and compared these with the GFP-negative fraction of the $\mathrm{S}+\mathrm{P}$ culture, which contains $<4 \%$ of pan- $\mathrm{MN}^{+}$neurons. RNA-seq reads were aligned to the reference human genome, normalized, and expression level of individual genes calculated as reads per kilobase per million mapped reads. The profiles of housekeeping gene GAPDH, neuronal marker neurofilament light chain NEFL, and motor neuron marker ISL1 corroborate the neuronal and motor neuron identity of sorted GFP-positive cells (Fig. 3A). Global analysis re- 
A

GAPDH

NEFL

ISL 1
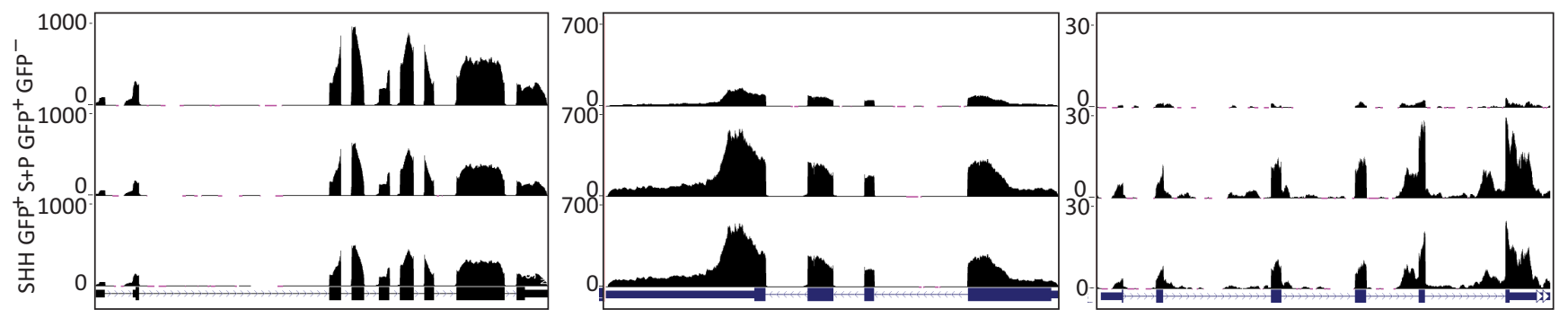

B
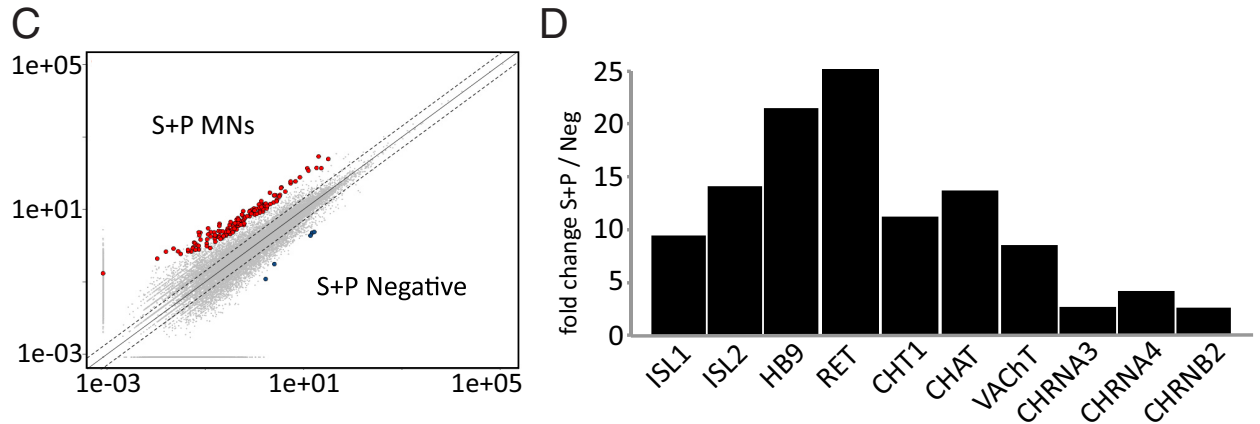

E

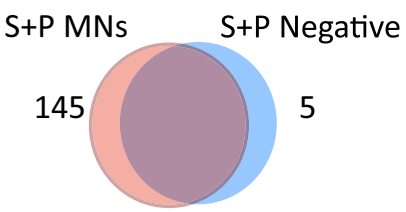

2 fold up, $P<0.001$

GO Analysis: 37 clusters

\begin{tabular}{|l|ll|}
\cline { 2 - 3 } \multicolumn{1}{c|}{} & enrichment & genes associated \\
\hline Cluster 1: & synaptic transmission & 21 \\
& transmission of nerve impulse & 21 \\
& cell-cell signaling & 25 \\
& neurological system process & 23 \\
\hline & $(1)$ neuron differentiation & 22 \\
& (2) neuron development & 19 \\
& (3) cell projection morphogenesis & 16 \\
& (4) neuron projection development & 16 \\
& (5) cell part morphogenesis & 16 \\
& (6) cell projection organization & 18 \\
& (7) axongenesis & 14 \\
& (8) cell morphogenesis involved in neuron & 14 \\
& differentiation & \\
& (9) neuron projection morphogenesis & 14 \\
& (10) cell morphogenesis involved in & 14 \\
& differentiation & \\
& (11) cell morphogenesis & 16 \\
& (12) cellular component morphogenesis & 16 \\
& (13) cell motion & 14 \\
& (14) axon guidance & 6 \\
\hline Cluster 3: & synapse & 21 \\
& synapse part & 17 \\
& plasma membrane part & 36 \\
& cell junction & 16 \\
& plasma membrane & 47 \\
\hline Cluster 4: & neuron projection & 17 \\
& axon & 18 \\
& cell projection & \\
& & \\
\end{tabular}

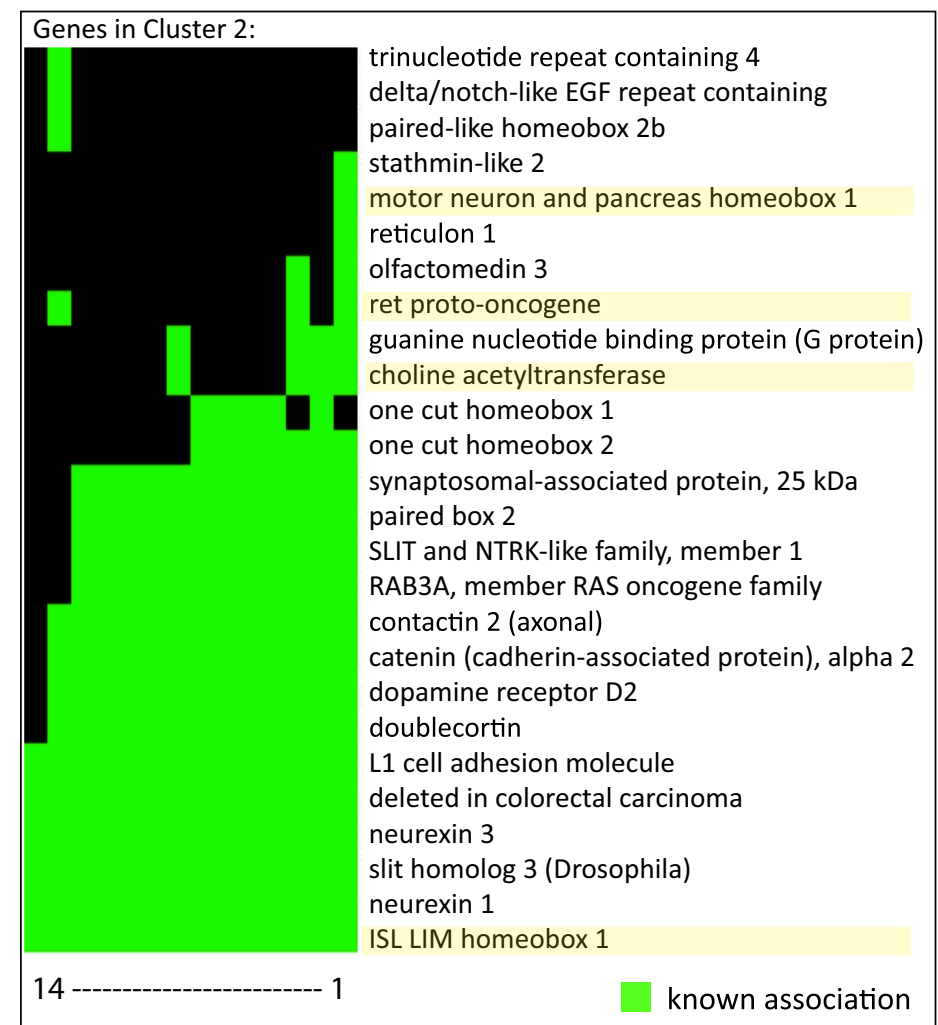

Figure 3. RNA-Seq analysis of $S+P$ - and SHH-derived motor neurons. A, Normalized reads from GAPDH, neurofilament light chain (NEFL), and ISL1 genes for $S+P$ non-motor neurons (GFP ${ }^{-}$), $S+\mathrm{P}$ - and SHH-derived motor neurons (GFP ${ }^{+}$) post-FACS (HUES3 Hb9::GFP line). Reads are normalized to the total number of map reads per sample. $\boldsymbol{B}$, Venn diagram of twofold ( $p<0.001$ ) enriched genes in S + P motor neurons (MNs) compared with S + P non-MNs (GFP ${ }^{-}$fraction). C, Scatter plot of S + P MNs versus $S+P$ non-MNs; red dots are the 145 genes enriched from $\boldsymbol{B}$, while the blue are the five down from $\boldsymbol{B}$. D. The set of cholinergic and MN-specific genes that are upregulated in the $S+P$ motor neuron fraction. $\boldsymbol{E}, \mathrm{GO}$ clustering of $S+P$ MNs versus non-MNs yields 37 clusters, of which the top clusters are highlighted. Right side of the chart is the genes from cluster 2, with known motor neuron genes highlighted in yellow; 1-14 on the right corresponds to 1-14 on the left.

vealed 145 genes enriched in $\mathrm{S}+\mathrm{P}$ motor neurons compared with their negative fraction (Fig. $3 B, C$ ). Markers of spinal motor neurons (ISL1, ISL2, HB9, RET) as well as key cholinergic genes (CHAT, CHT1, VACHT, CHRNA3, CHRNA4, CHRNB2) were enriched in GFP-positive cells (Fig. 3D). For example, HB9 was enriched 21.6-fold and CHT1 13.7-fold. Unbiased gene ontology (GO) analysis revealed that transmission of nerve impulses, neuronal development and differentiation, synaptic transmission, 
and axon pathfinding were the top four sets of cellular processes defining S + P-derived GFP-positive cells (Fig. 3E). Importantly, the cluster of genes associated with neuronal development and differentiation contained key motor neuron markers (MNX1 (HB9), RET, CHAT, ISL1) (Fig. 3E), further supporting the conclusion that the $\mathrm{S}+\mathrm{P}$-differentiated cells acquired motor neuron identity.

\section{Preferential generation of FOXP1-expressing motor neurons under $\mathrm{S}+\mathrm{P}$ conditions}

A crucial step in motor neuron maturation is the acquisition of a defined columnar subtype identity. Based on the mutually exclusive expression of LHX3 3 and FOXP1 transcription factors, motor neurons in chick and mouse embryos can be subdivided into three major categories: MMC neurons that express LHX3 and innervate axial muscles, LMC neurons that innervate the limb muscles and express FOXP1, and finally the HMC neurons that express neither FOXP1 or LHX3 and innervate the hypaxial muscles (Dasen et al., 2008). We first asked whether differential expression of LHX3 and FOXP1 could be used to determine motor neuron columnar identities in developing human spinal cord (Fig. 4A). Consistent with the pattern of expression in the developing chick and mouse spinal cord (Dasen et al., 2008; Otaegi et al., 2011), strong FOXP1 immunoreactivity was detected in lateral $\mathrm{HB}^{+}{ }^{+}$or ISL $1^{+}$motor neurons at limb levels as expected for LMC neurons (Fig. $4 A, B$ ), and in a small number of scattered $\mathrm{HB}^{-}{ }^{-} / \mathrm{ISL}^{-}{ }^{-}$cells outside of the ventral horn, which are presumptive interneurons. LHX3 marked the most medial group of presumptive MMC motor neurons, and a more dorsally located group of interneurons (Fig. 4A,B). Lateral to MMC neurons we observed a group of motor neurons that lacked expression of both FOXP1 and LHX3, which is consistent with an HMC identity (Fig. $4 A$, right). Based on these studies we conclude that similar to the chick and mouse, expression of LHX3 and FOXP1 in human embryonic spinal cord distinguishes motor neurons of different columnar subtype identities.

We examined expression levels of FOXP1 and LHX3 in the RNA-seq data. Comparison of profiles of GFP-positive cells revealed an $\sim 1.3$-fold increase in FOXP1 and an $\sim 1.8$-fold decrease in LHX3 RNA levels in S + P as compared with SHH motor neurons, suggesting that the two differentiation protocols might yield motor neurons of different columnar subtype identities. We confirmed the increase in FOXP1 and decrease in LHX3 RNA levels in S + P motor neurons by qPCR analysis in three independent biological samples of purified $\mathrm{GFP}^{+}$motor neurons (Fig. $4 C)$. Immunostaining revealed that $\mathrm{S}+\mathrm{P}$-differentiated cultures contained significantly higher percentages of $\mathrm{FOXP}^{+}$motor neurons ( $68 \pm 4 \%, n=6$ biological replicates; Fig. $4 D, E$ ), and a corresponding decrease in the number of motor neurons expressing LHX3 ( $9 \pm 3 \%$ of S + P motor neurons compared with $64 \pm 2 \%$ of SHH motor neurons) (Fig. $4 D, E$ ). Importantly, FOXP1 and LHX3 were expressed in a nonoverlapping manner indicating proper segregation of columnar subtype identities in cultured human motor neurons (data not shown). FOXP1 ${ }^{+}$cells expressing GFP under S + P conditions exhibited neuronal morphology and stained for a nonphosphorylated form of heavy neurofilament (SMI-32) that, within the spinal cord in vivo, is selectively expressed in motor neurons (Clowry et al., 2005) (Fig. $4 F)$. Using colabeling for FOXP1 and pan-MN as a criterion to identify LMC motor neurons we expanded our analysis to a set of six additional iPSC lines generated from healthy donors and patients with ALS. We quantified the percentage of $\mathrm{FOXP}{ }^{+}$motor neurons and found that the $\mathrm{S}+\mathrm{P}$ method generated on average $62 \pm 3 \%$ LMC motor neurons, consistent with our hESC study (Fig. $4 G$ ).

To further substantiate the LMC identity of S + P-generated motor neurons we examined the expression of another LMC marker, RALDH2 (Sockanathan and Jessell, 1998; Nédelec et al., 2012). In human spinal cords, RALDH2 immunoreactivity was largely restricted to the cytoplasm of FOXP1 ${ }^{+}$LMC neurons at limb levels (Fig. 4H). qPCR analysis revealed an increase in LMC marker RALDH2 expression in S + P-differentiated motor neurons (Fig. 4C), but RALDH2 staining of dissociated cultures produced only a weak signal that was difficult to interpret. However, when S + P-derived embryoid bodies were plated on laminincoated substrata we observed a subset of $\mathrm{GFP}^{+}$motor axons that were colabeled with anti-RALDH2 antibodies, further supporting the notion that motor neurons differentiated under the $\mathrm{S}+\mathrm{P}$ condition acquired LMC columnar identity (Fig. 4I).

Rodent, avian, and human LMC neurons are found in brachial and lumbar spinal domains harboring motor neurons innervating fore/upper and hind/lower limbs, respectively (Dasen et al., 2008, Fig. 4A, and data not shown). Brachial and lumbar LMC neurons can be distinguished by their respective expression of HOX6 and HOX10 transcription factors. Brachial LMC can be further subdivided into a rostral segment expressing HOXA5 transcription factor and caudal HOXC8-positive domain (Dasen et al., 2009). To refine the identity of these LMC neurons we examined the expression of HOX genes in hESCs differentiated under the $\mathrm{S}+\mathrm{P}$ condition. We determined that differentiated cells exhibit elevated levels of HOXA5, HOXC6 (6.03 and 23.8, $\mathrm{S}+\mathrm{P}$ fold change over ESCs, respectively), and to a lesser extent HOXC8 expression compared with undifferentiated ESCs. In contrast we did not detect significant expression of HOXC9 or HOXC10 (Fig. 5A, and data not shown), indicating that the motor neurons are primarily of rostral brachial identity.

\section{Divisional identity of FOXP1-expressing motor neurons}

To further characterize the LMC neurons generated using $\mathrm{S}+\mathrm{P}$ we asked to which division of the LMC they belonged (Fig. 5B). Motor neurons in the lateral division of the $\mathrm{LMC}\left(\mathrm{LMC}_{1}\right)$ express LHX1 and HB9 in vivo (Palmesino et al., 2010; Fig. 5C), while those in the medial LMC $\left(\mathrm{LMC}_{\mathrm{m}}\right)$ express FOXP1 and ISL1 while lacking LHX1 (Fig. 5B; Thaler et al., 2004; Palmesino et al., 2010). Interestingly, a substantial portion of $\mathrm{LMC}_{\mathrm{m}}$ neurons in the human spinal cord also coexpress ISL1 and HB9 (Fig. 2G). Analysis of the LMC population by HB9 and ISL1 expression in both SHH- and S + P-derived FOXP1 motor neurons revealed that under both conditions most FOXP1 cells expressed ISL1 (either alone or in combination with $\mathrm{HB} 9$ ), suggestive of an $\mathrm{LMC}_{\mathrm{m}}$ identity (Fig. $5 D$ ). The remaining $20 \pm 1 \%$ of the $\mathrm{S}+\mathrm{P} \mathrm{FOXP1}^{+}$ motor neurons expressed HB9 only, indicating that these might be of $\mathrm{LMC}_{1}$ identity. However, very few of these ISL1 ${ }^{-} \mathrm{HB9}^{+}$ FOXP $1{ }^{+}$motor neurons expressed LHX1 $(2 \pm 1 \%)$ (Fig. $\left.5 E\right)$, a definitive marker for $\mathrm{LMC}_{1}$ motor neurons in vivo (Fig. $5 C$ ), raising the possibility that in vitro conditions do not support full maturation of LMC subtype identity by $21 \mathrm{~d}$ in culture. The $\mathrm{HB}^{+}{ }^{+} \mathrm{FOXP}^{+}{ }^{+} \mathrm{LHX1}^{-}$cells might be $\mathrm{LMC}_{\mathrm{m}}$ - neurons that failed to downregulate $\mathrm{HB} 9$ or $\mathrm{LMC}_{1}$ neurons that failed to acquire LHX1.

Exposure of nascent LMC motor neurons to high concentrations of RA promotes specification of $\mathrm{LMC}_{1}$ identity (Sockanathan and Jessell, 1998). We therefore tested whether culturing $\mathrm{S}+\mathrm{P}$ generated LMC neurons in the presence of high concentrations of RA would increase the number of cells displaying 
A

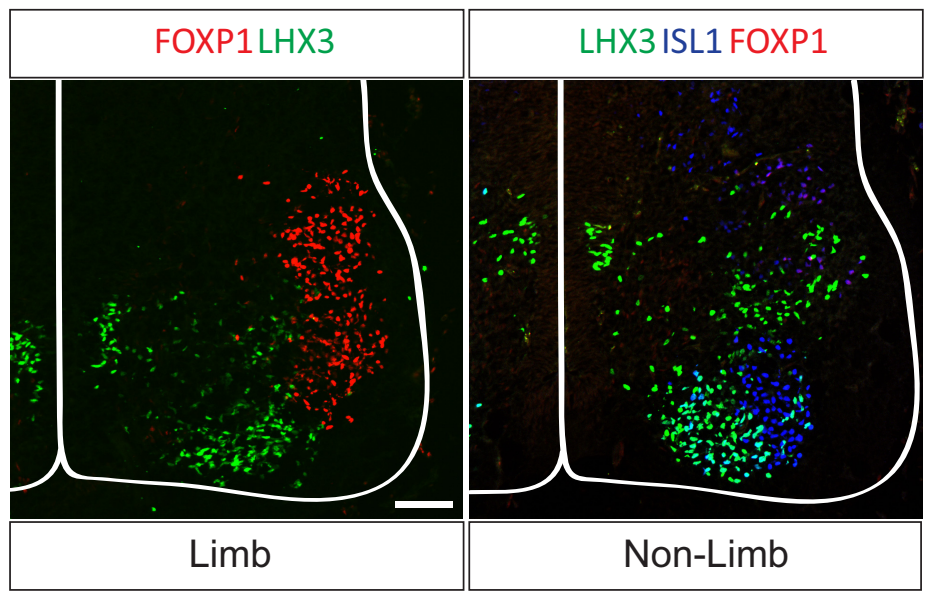

B

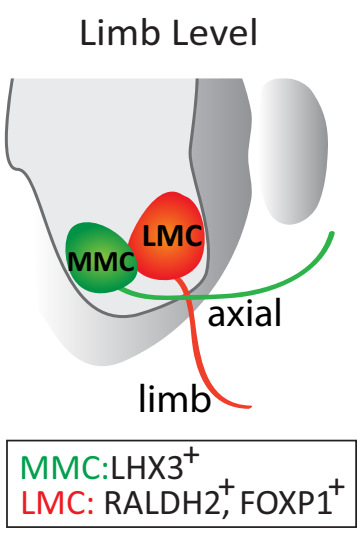

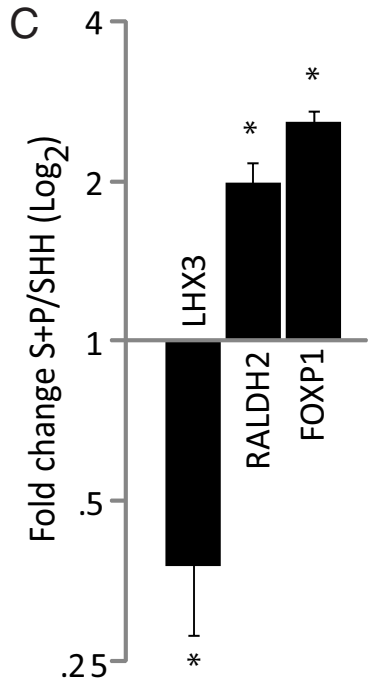
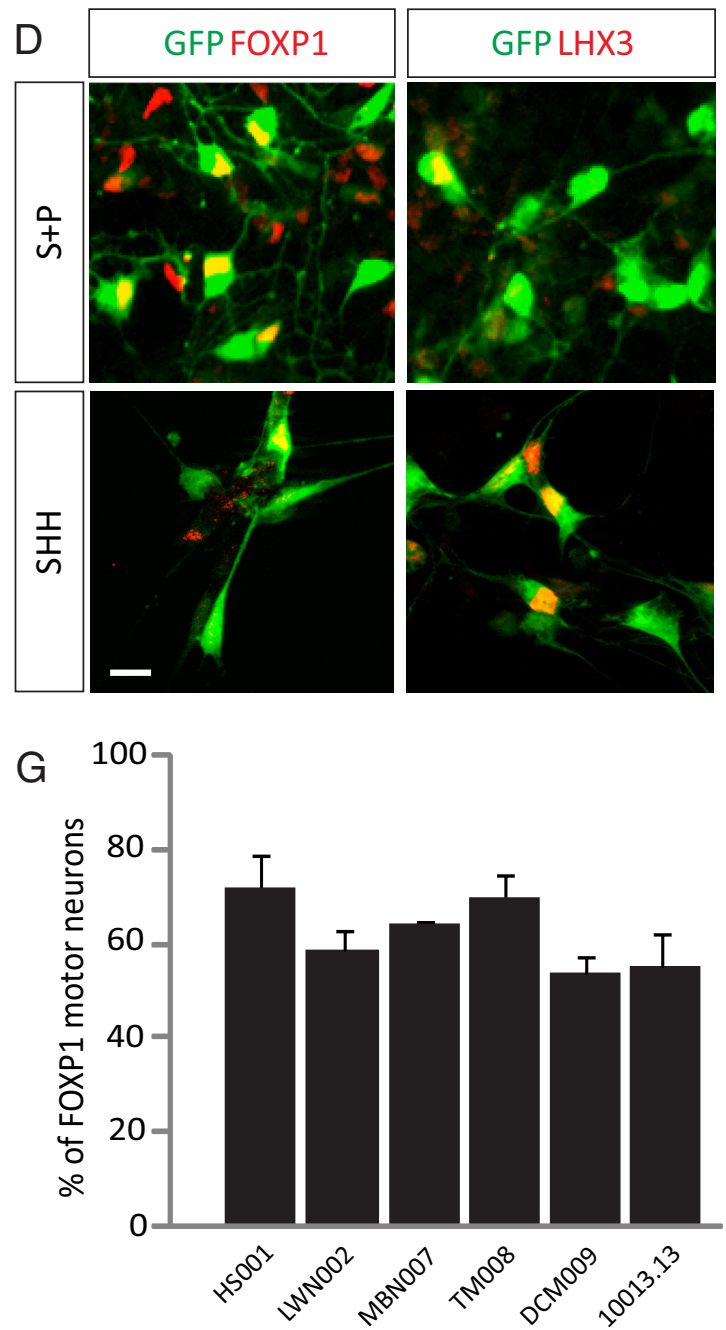

E

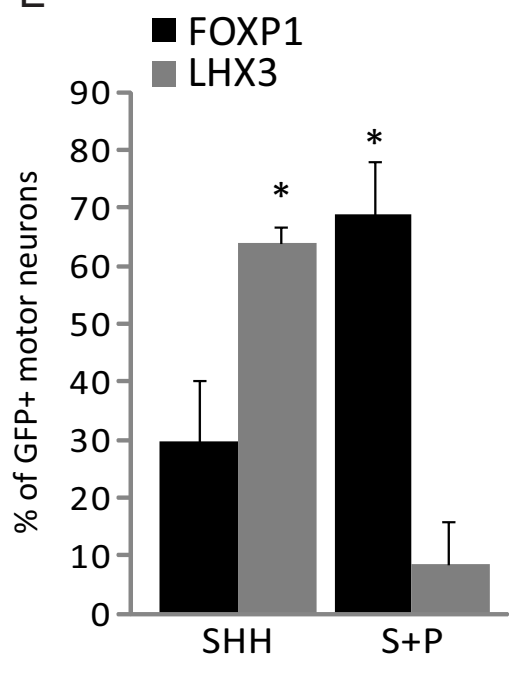

$\mathrm{H}$

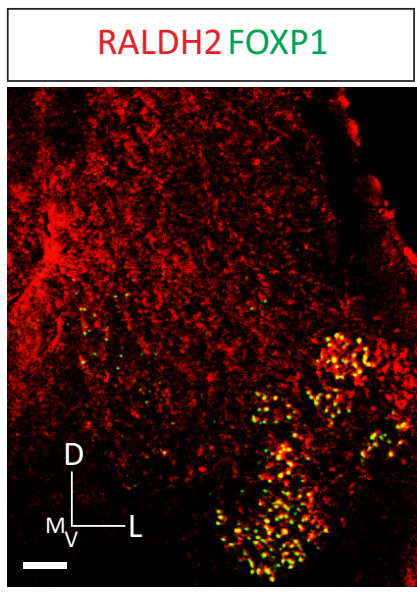

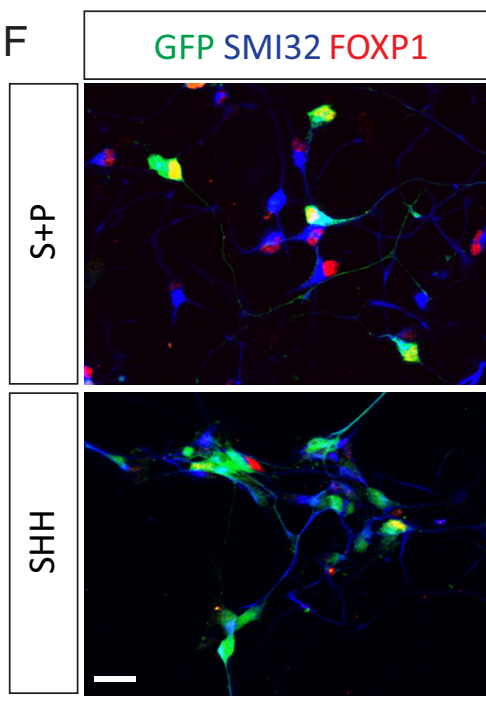

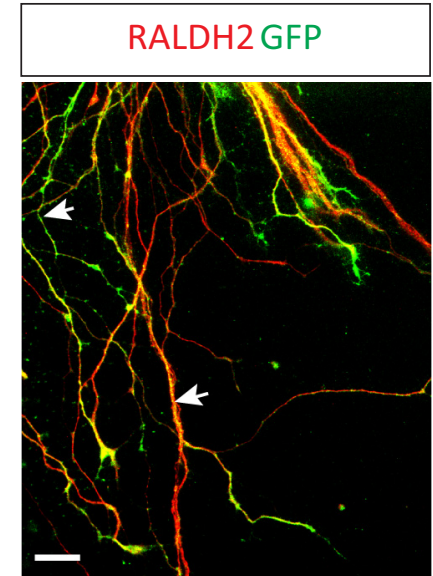

Figure 4. FOXP1 ${ }^{+}$motor neurons are generated using the $S+P$ method. $A$, Representative images of human embryonic spinal cords from both the limb level and nonlimb level for F0XP1 (red), LHX3 (green), and ISL1 (blue). B, Schematic representation of the spinal cord at the limb level showing the MMC (LHX3) and the LMC (RALDH2, F0XP1). C, qPCR showing the $\log$ fold change of $S+P$ to SHH-derived purified motor neurons $\left(n=3, \log\right.$ base $\left.2,{ }^{*} p<0.05\right)$. D, Representative image of SHH- and $S+P$-derived motor neurons (GFP) with F0XP1 (left) and LHX3 (right) using the Hb9::GFP reporter. $\boldsymbol{E}$, Quantification of immunostained dissociated cultures using either $S+P$ or $S H H\left(n=6,{ }^{*} p<0.001\right)$. $\boldsymbol{F}$, Representative image of F0XP1, SMI-32, and GFP from SHH- and S + P-derived cultures using the Hb9::GFP reporter. G, Quantification from six additional stem cell lines (iPS from ALS patients and controls) showing FOXP1 ${ }^{+}$motor neurons generated with the $S+P$ method. $\boldsymbol{H}$, Human spinal cord at 10 weeks, RALDH2 in red with F0XP1 in green. $\boldsymbol{I}$, RALDH2 expression in a subset of GFP ${ }^{+}$ neurites; outgrowth from a plated EB (day $21+48 \mathrm{~h}$ ). Arrows indicate a GFP ${ }^{+}$neurite without RALDH2 (top left), and an RALDH2 ${ }^{+}$GFP ${ }^{+}$neurite. Scale bars: (for $\boldsymbol{A}, \boldsymbol{H}$ ) $100 \mu \boldsymbol{\mu m}$; (for $\boldsymbol{D}, \boldsymbol{F}) 10 \mu \mathrm{m}$; (for I ) $50 \mu \mathrm{m}$. Data presented as mean \pm SD. 
A
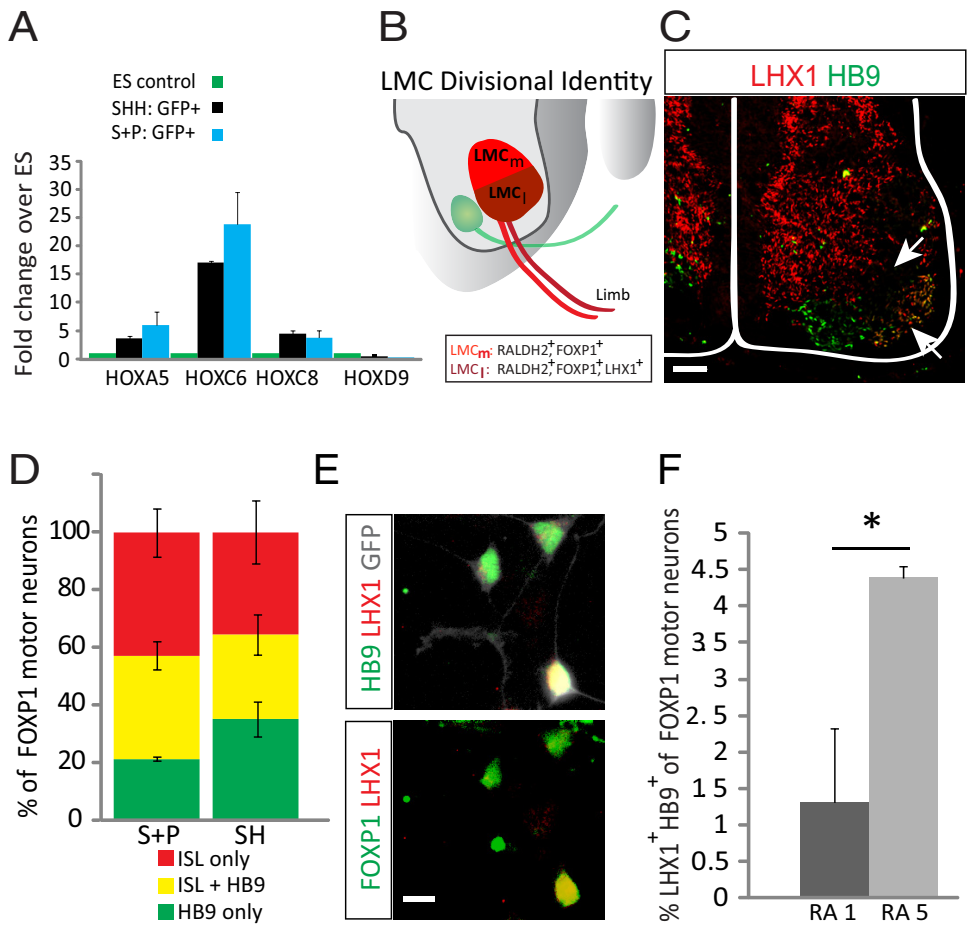

$\mathrm{E}$
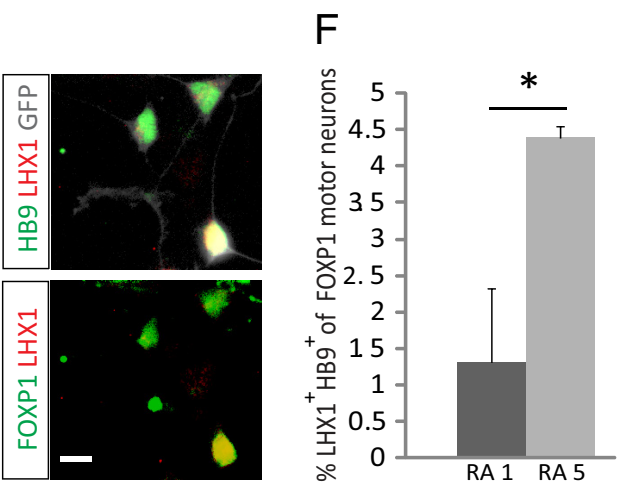

Figure 5. LMC diversity generated using the $S+P$ method. $A, q P C R$ data showing the fold change of $S+P$ - and $S H H$-derived $\mathrm{GFP}^{+}$FACS purified motor neurons compared with ESCs for HOX genes. $\boldsymbol{B}$, Schematic representation of the spinal cord at the limb level showing the LMC $C_{m}$ (RALDH2, FOXP1) and LMC (RALDH2, FOXP1, LHX1). C, Human spinal cord at the brachial-limb level for LHX1 (red) and HB9 (green). Top arrow indicates area without LHX1 (the LMC $C_{m}$ region), and bottom arrow highlights the LMC, $D_{\text {, }}$ Quantification of FOXP1 ${ }^{+}$motor neurons for HB9, ISL1, and pan-MN expression from both SHH- and S + P-derived cultures from the $\mathrm{Hb}$ 9::GFP reporter line. $\boldsymbol{E}$, Representative image of a GFP ${ }^{+}$motor neuron (gray) that expresses HB9, LHX1 (top) and FOXP1, LHX1 (bottom). $\boldsymbol{F}$, Treatment with RA $5 \mu$ m over $3 \mathrm{~d}$ showed an increase in LHX $1^{+}$FOXP $1{ }^{+}$motor neurons $(p=0.036)$ using the Hb9:GFP reporter. Scale bars: (for $\boldsymbol{C}) 100 \mu \mathrm{m}$; (for $\boldsymbol{E}) 10 \mu \mathrm{m}$. Data presented as mean \pm SEM.

$\mathrm{LMC}_{1}$ character. Indeed, culturing day 21 motor neurons in the presence of $5 \mu \mathrm{M}$ RA for $3 \mathrm{~d}$ postplating significantly increased the fraction of $\mathrm{LMC}_{1}$ neurons, as judged by the coexpression of LHX1 and HB9 within the FOXP1 ${ }^{+}$motor neuron population $(1.3 \pm 1 \%$ using $1 \mu \mathrm{M}$ RA vs $4.4 \pm 0.2 \%$ using $5 \mu \mathrm{M}$ RA, $p<0.05$; Fig. $5 F)$. Together, these observations indicate that $\mathrm{S}+\mathrm{P}$ motor neurons acquire a predominantly $\mathrm{LMC}_{\mathrm{m}}$ phenotype and that acquisition of $\mathrm{LMC}_{1}$ identity can be potentiated by the treatment of differentiating cells with a high concentration of RA.

\section{Functional characterization of motor neurons generated by the accelerated protocol}

To determine whether the accelerated FOXP1 ${ }^{+} \mathrm{S}+\mathrm{P}$ cultures yielded functional motor neurons, we investigated their behavior in vitro and in vivo. We previously reported that human ES/iPS-derived motor neurons display spontaneous activity and generate $\mathrm{Ca}^{2+}$ transients upon exposure to the glutamate receptor agonist KA by day 35 of differentiation (Boulting et al., 2011). To determine whether functional maturation keeps pace with the accelerated appearance of molecular markers, day $21 \mathrm{~S}+$ P-generated LMC motor neurons were FACS-purified based on GFP intensity. We first confirmed that FACS-purified cells maintained their LMC identity in culture (Fig. 6A,B). Motor neurons were cultured for $6 \mathrm{~d}$ then loaded with Fluo-4 AM, a $\mathrm{Ca}^{2+}$ sensitive indicator. Overall, $62 \pm 5 \%$ (cells $=58$ ) showed spontaneous variations in $\mathrm{Ca}^{2+}$ transients (Fig. 6C) and all cells responded to a brief pulse of KA with a large increase in Fluo-4 fluorescence intensity that returned rapidly to baseline levels (cells $=17$; Fig. $6 D, E)$. Similar results were obtained using the $\mathrm{H} 9 \mathrm{hESC}$ line $(60 \pm 1 \%$ spontaneous activity; cells $=63$ ) or $\mathrm{SHH}$ motor neurons at day $31+6(57 \pm 3 \%$; cells $=$ 58). To determine whether $S+P$-derived motor neurons are capable of firing APs, whole-cell patch current-clamp recordings were performed using GFP-positive HUES3 Hb9::GFP cells. In all cells tested $(n=9)$, APs could be evoked by $20-50$ pA, 1 s current injections (Fig. 6F). These results suggest that motor neurons derived using the accelerated $\mathrm{S}+\mathrm{P}$ protocol acquire physiological properties consistent with functional motor neurons, and are as mature as motor neurons derived under the standard $31 \mathrm{~d} \mathrm{SHH}$ protocol.

Motor neurons are the only CNS neurons that innervate peripheral tissues. To study the ability of $\mathrm{S}+\mathrm{P}$ motor neurons to project axons toward the muscle targets, differentiated cells were transplanted in ovo into the lesioned neural tube of chicken embryos at $\mathrm{HH}$ stage 15-16 (Fig. 6G; Wichterle et al., 2002; Lee et al., 2007b; Peljto et al., 2010). A majority $(86 \%)$ of transplanted embryos showed successful engraftment of human motor neurons (as marked by GFP expression) into the ventral horn $(n=7)$. Importantly, we observed GFPlabeled axons of grafted motor neurons projecting through the ventral (and more rarely, dorsal) roots and along the peripheral nerves of the host in all of the successfully transplanted chicken embryos $(n=6$ of 7 ) (Fig. $6 G$ ). These data indicate that human motor neurons generated by the accelerated protocol exhibit proper ability to extend their axons outside of the CNS and follow typical motor nerve trajectories.

\section{Discussion}

We describe a novel approach for high-yield, high-abundance production of motor neurons from human stem cells with a defined and controllable subtype identity. The protocol generates motor neurons within 3 weeks using only small-molecule compounds to drive neuralization, caudalization, and ventralization of precursors. Despite the accelerated differentiation, the resulting motor neurons express HB9 and ISL1 in a manner that closely resembles the pattern observed in human motor neurons in vivo and exhibit functional properties similar to those of primary rodent neurons. They also have a clear motor neuron-like signature by immunocytochemistry, qPCR, and RNA-seq profiling. Unexpectedly, the new method also produced highly enriched populations of limb-innervating motor neurons, which are of fundamental interest to developmental studies and disease modeling.

Human ESCs and iPSCs represent a potentially valuable resource for modeling human developmental biology and neurodegenerative disease in vitro (Kanning et al., 2010; Liu and Zhang, 2010; Han et al., 2011). However, development of successful cellbased assays has been hindered by the long duration and low 
A

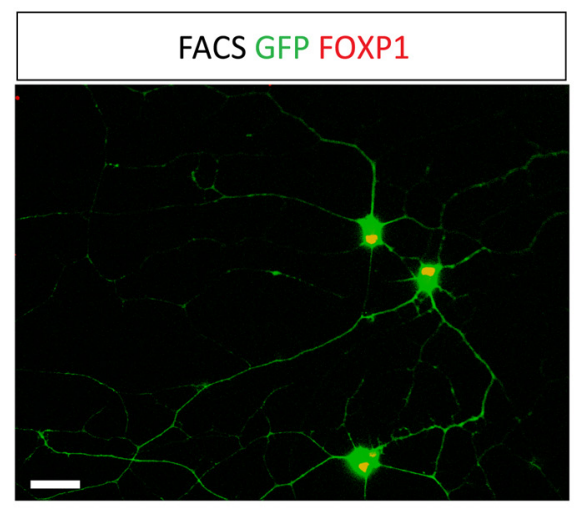

D

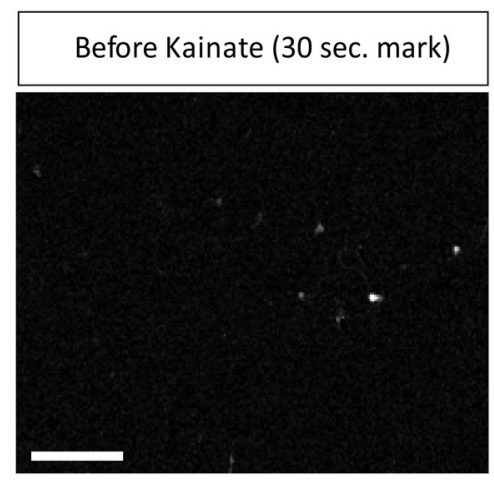

E

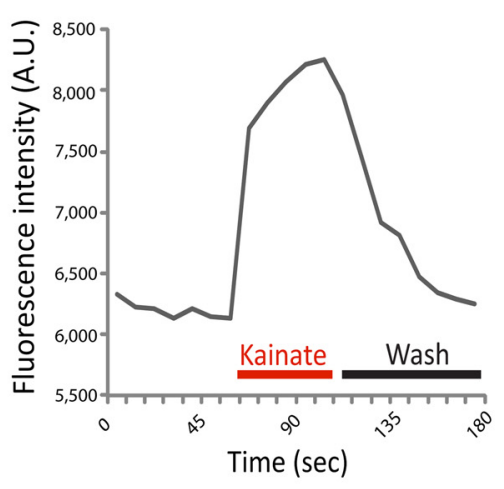

B

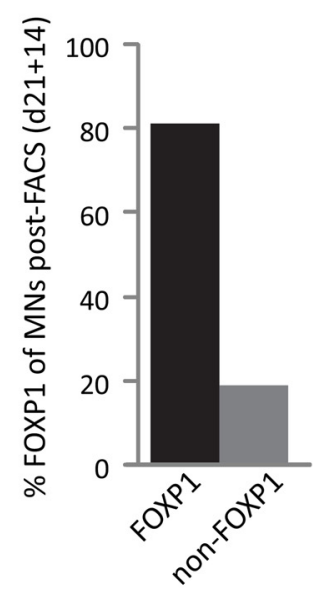

C

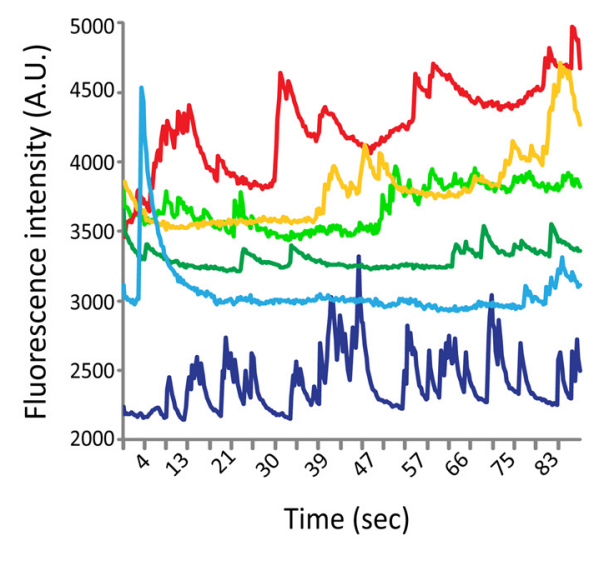

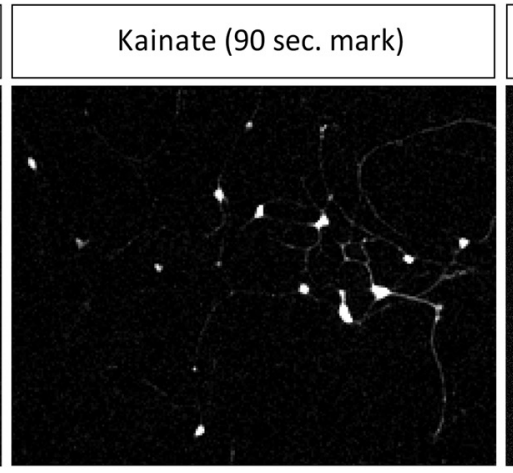

F

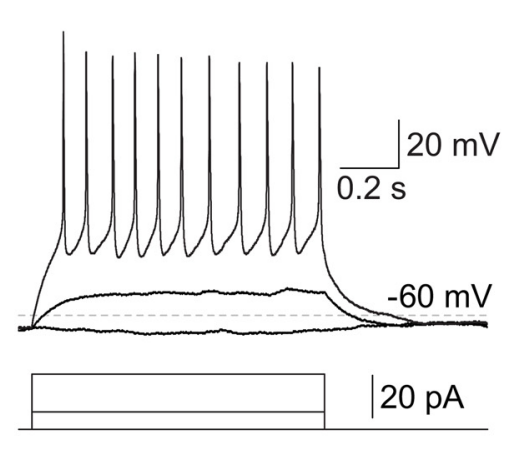

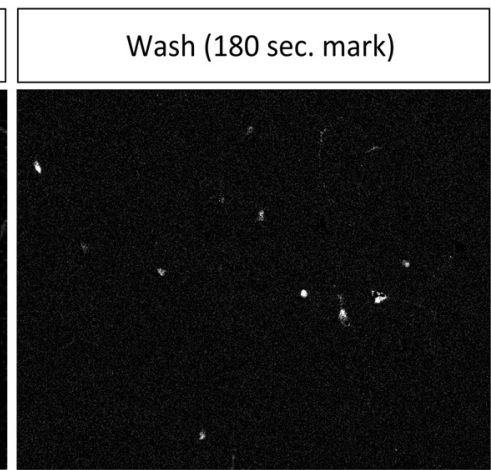

G

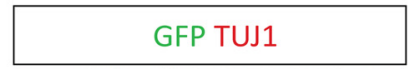

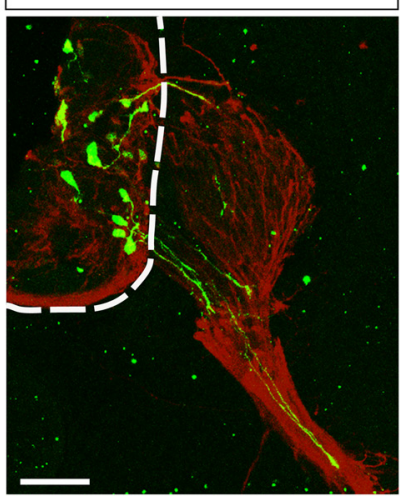

Figure 6. Functional properties of $S+P$ motor neurons. A, Representative image of HUES3 Hb9::GFP motor neurons stained for GFP and FOXP1 post-FACS. B, Quantification of FOXP1, $21+14 \mathrm{~d}$. C, Fluorescence intensity recorded over 90 s show spontaneous $\mathrm{Ca}^{2+}$ transients occurred in neurons loaded with Fluo-4 AM Ca ${ }^{2+}$ indicator. Representative traces of active cells are shown. $\boldsymbol{D}$, Fluorescence images showing the same field of motor neurons (day $21+6)$ loaded with Fluo-4 $\mathrm{Ca}^{2+}$ indicator before, during, and after KA application. $\boldsymbol{E}$, Representative trace showing fluorescence intensities measured from a single motor neuron before and after a brief application of $100 \mu \mathrm{m} \mathrm{KA}$. F, Current-clamp recording obtained from a GFP-positive HUES3 Hb9::GFP cell differentiated using the $S+$ P protocol, day $21+7$. Three membrane potential traces in response to different amplitudes of current injection are overlaid. The current command step is shown under the membrane traces. The selected traces show the membrane potential in the absence of a current step, a subthreshold current step $(8 \mathrm{pA})$, and a current step sufficient to elicit a train of action potentials (26 pA). G, Representative image of xenotransplantation into a developing chicken embryo. Human $H 69$ ::GFP, green; TUJ1. red. A.U. is arbitrary units. Scale bars: (for $\boldsymbol{A}) 25 \mu \mathrm{m}$; (for $\boldsymbol{D}, \boldsymbol{G}) 50 \mu \mathrm{m}$.

efficiency of many differentiation protocols. Optimization of motor neuron differentiation depends on the development of unbiased methods for motor neuron quantification in cultures. Our analysis of HB9 and ISL1 expression in the developing human spinal cord reveals that these markers are expressed only in subsets of spinal motor neurons. To prevent underestimating yields, or missing a subset of motor neurons, we therefore relied on a combined expression of the two markers (pan-MN staining). To further eliminate any bias in quantification resulting from analysis of select embryoid bodies or clumps of adherent cells in cultures, differentiated cells were dissociated followed by either flow cytometry (in the case of $H b 9::$ GFP reporter) or semi-automated randomized sampling of fields of plated cells immunostained for HB9/ISL1 expression. The acquired images were analyzed using the MetaMorph software package to further reduce potential experimenter bias. We propose the adoption of this approach as a standard method for quantification of motor neuron yields, as it will allow future cross- 
comparisons of differentiation protocols between different investigators and labs.

Using this quantification method, we performed a systematic optimization of motor neuron differentiation using off-the-shelf small-molecule analogs of patterning factors. Since the initial neuralization step had already been optimized (Chambers et al., 2009; Boulting et al., 2011), we focused on the subsequent steps of caudalization and ventralization, aiming to specify ventral spinal motor neuron progenitors with high efficiency. The resulting procedure, using RA, SAG, and PUR, is robust, efficient, and reduces the time and cost of the procedure, making human stem cell-derived motor neurons a more widely accessible reagent.

Accelerating the speed of motor neuron specification raised a concern as to whether the resulting motor neurons would acquire definitive motor neuron physiological properties. Previous reports using either $\mathrm{Ca}^{2+}$ imaging at 35 DIV (Boulting et al., 2011), or electrophysiological recording (Singh Roy et al., 2005; Lee et al., 2007b; Li et al., 2008; Takazawa et al., 2012) have demonstrated that stem cell-derived motor neurons become electrically active with prolonged time in culture. Despite their accelerated differentiation, the motor neurons derived by the $\mathrm{S}+\mathrm{P}$ protocol exhibit spontaneous $\mathrm{Ca}^{2+}$ transients, fire APs, and project axons along major motor nerves upon transplantation to the developing chick spinal cord, paving the way for follow-up studies of the in vivo behavior of human motor neuron subtypes (Peljto et al., 2010; Patani et al., 2011).

We observed that the majority of $S+P$ neurons acquired the identity of limb-innervating LMC motor neurons. This was a surprising finding, as most of the current differentiation protocols for mouse or human motor neurons yield predominantly the MMC motor neuron subtype (Wichterle et al., 2002; Patani et al., 2011). While most of the limb-innervating motor neurons $(\sim 80 \%)$ expressed markers consistent with $\mathrm{LMC}_{\mathrm{m}}$ divisional identity, retinoic acid treatment promoted specification of $\mathrm{LMC}_{1}$ identity, demonstrating that in vitro-derived LMC motor neurons are responsive to developmental cues controlling motor neuron subtype differentiation. Mechanisms that underlie specification of columnar identity have been a focus of several recent studies. The expression of the LMC determinant FOXP1 in the developing mouse and chick spinal cord is controlled by a rostrocaudally restricted expression of brachial and lumbar Hox genes (Dasen et al., 2008). Establishment of MMC identity, on the other hand, relies on noncanonical Wnt signals expressed by ventrally located floor plate cells (Agalliu et al., 2009). Thus, the observed increase in the number of FOXP1-positive motor neurons might be a result of efficient ventralization of embryoid bodies expressing limb-level Hox genes in combination with an inhibition of noncanonical Wnt signaling. Alternatively, S $+\mathrm{P}$ conditions might accelerate maturation of LMC motor neurons present under all differentiation conditions presented in this study, leading to rapid downregulation of LHX3 and acquisition of FOXP1 expression. The in vitro system described in this study also provides a unique opportunity to characterize the molecular pathways controlled by SAG and PUR leading to the acquisition of LMC motor neuron identity.

In conclusion, we have established reference expression profiles of principal motor neuron markers in the human developing spinal cord, and relying on these maps we developed an efficient, rapid, and technically simple protocol for differentiation of human pluripotent stem cells into motor neurons acquiring preferentially either LMC or MMC columnar identity, without the use of recombinant proteins or viral factors (Hester et al., 2011; Son et al., 2011). Efficient specification of the LMC motor neuron fate from pluripotent stem cells will provide experimental tools for building more sophisticated in vitro models of neural development, motor circuit function, and more refined transplantation assays. Furthermore, in a disease context, motor neurons exhibit subtype-specific differences in their susceptibility to degeneration. Whereas MMC and HMC are affected predominantly in SMA, nonbulbar onset ALS is typically manifested by initial weakness in distal limb muscles innervated by LMC neurons (Theys et al., 1999; Kanning et al., 2010). Together, derivation of cultures in which motor neuron subtype identity can be controlled with great efficiency provides a potential basis for modeling selective disease sensitivity of motor neuron subtypes in vitro and for designing targeted cell-based screens for motor neuron disease therapeutics.

\section{Notes}

Supplemental material for this article is available at http://scholar. harvard.edu/amorosornaseq/Figure3. Supplemental RNA-Seq data: this is the list of 145 significantly ( $p<0.001,>2$-fold) upregulated genes in the $\mathrm{S}+\mathrm{P}$-derived motor neurons $\left(\mathrm{GFP}^{+}\right.$, FACS purified) and the five genes significantly downregulated. This material has not been peer reviewed.

\section{References}

Agalliu D, Takada S, Agalliu I, McMahon AP, Jessell TM (2009) Motor neurons with axial muscle projections specified by Wnt $4 / 5$ signaling. Neuron 61:708-720. CrossRef Medline

Arber S, Han B, Mendelsohn M, Smith M, Jessell TM, Sockanathan S (1999) Requirement for the homeobox gene $\mathrm{Hb} 9$ in the consolidation of motor neuron identity. Neuron 23:659-674. CrossRef Medline

Bock C, Kiskinis E, Verstappen G, Gu H, Boulting G, Smith ZD, Ziller M, Croft GF, Amoroso MW, Oakley DH (2011) Reference maps of human ES and iPS cell variation enable high-throughput characterization of pluripotent cell lines. Cell 144:439-452. CrossRef Medline

Boulting GL, Kiskinis E, Croft GF, Amoroso MW, Oakley DH, Wainger BJ, Williams DJ, Kahler DJ, Yamaki M, Davidow L (2011) A functionally characterized test set of human induced pluripotent stem cells. Nat Biotechnol 29:279-286. CrossRef Medline

Chambers SM, Fasano CA, Papapetrou EP, Tomishima M, Sadelain M, Studer L (2009) Highly efficient neural conversion of human ES and iPS cells by dual inhibition of SMAD signaling. Nat Biotechnol 27:275-280. CrossRef Medline

Clowry GJ, Moss JA, Clough RL (2005) An immunohistochemical study of the development of sensorimotor components of the early fetal human spinal cord. J Anat 207:313-324. CrossRef Medline

Cowan CA, Klimanskaya I, McMahon J, Atienza J, Witmyer J, Zucker JP, Wang S, Morton CC, McMahon AP, Powers D, Melton DA (2004) Derivation of embryonic stem-cell lines from human blastocysts. N Engl J Med 350:1353-1356. CrossRef Medline

Dasen JS, De Camilli A, Wang B, Tucker PW, Jessell TM (2008) Hox repertoires for motor neuron diversity and connectivity gated by a single accessory factor, FoxP1. Cell 134:304-316. CrossRef Medline

Dasen JS, Jessell TM (2009) Chapter six Hox networks and the origins of motor neuron diversity. Curr Top Dev Biol 88:169-200. CrossRef Medline

Di Giorgio FP, Boulting GL, Bobrowicz S, Eggan KC (2008) Human embryonic stem cell-derived motor neurons are sensitive to the toxic effect of glial cells carrying an ALS-causing mutation. Cell Stem Cell 3:637-648. CrossRef Medline

Dimos JT, Rodolfa KT, Niakan KK, Weisenthal LM, Mitsumoto H, Chung W, Croft GF, Saphier G, Leibel R, Goland R, Wichterle H, Henderson CE, Eggan K (2008) Induced pluripotent stem cells generated from patients with ALS can be differentiated into motor neurons. Science 321:1218-1221. CrossRef Medline

Ebert AD, Yu J, Rose FF Jr, Mattis VB, Lorson CL, Thomson JA, Svendsen CN (2009) Induced pluripotent stem cells from a spinal muscular atrophy patient. Nature 457:277-280. CrossRef Medline

Frank-Kamenetsky M, Zhang XM, Bottega S, Guicherit O, Wichterle H, Dudek H, Bumcrot D, Wang FY, Jones S, Shulok J, Rubin LL, Poerter JA (2002) Small-molecule modulators of Hedgehog signaling: identifica- 
tion and characterization of Smoothened agonists and antagonists. J Biol 1:10. CrossRef Medline

Friedman BA, Maniatis T (2011) ExpressionPlot: a web-based framework for analysis of RNA-Seq and microarray gene expression data. Genome Biol 12:R69. CrossRef Medline

Han Steve SW, Williams Luis A, Eggan Kevin C (2011) Constructing and deconstructing stem cell models of neurological disease. Neuron 70:626-644.

Hester ME, Murtha MJ, Song S, Rao M, Miranda CJ, Meyer K, Tian J, Boulting G, Schaffer DV, Zhu MX, Pfaff SL, Gage FH, Kaspar BK (2011) Rapid and efficient generation of functional motor neurons from human pluripotent stem cells using gene delivered transcription factor codes. Mol Ther 19:1905-1912. CrossRef Medline

Hu BY, Zhang SC (2009) Differentiation of spinal motor neurons from pluripotent human stem cells. Nat Protoc 4:1295-1304. CrossRef Medline

Huang da W, Sherman BT, Lempicki RA (2009a) Bioinformatics enrichment tools: paths toward the comprehensive functional analysis of large gene lists. Nucleic Acids Res 37:1-13. CrossRef Medline

Huang da W, Sherman BT, Lempicki RA (2009b) Systematic and integrative analysis of large gene lists using DAVID bioinformatics resources. Nat Protoc 4:44-57. CrossRef Medline

Kanning KC, Kaplan A, Henderson CE (2010) Motor neuron diversity in development and disease. Annu Rev Neurosci 33:409-440. CrossRef Medline

Kriks S, Shim JW, Piao J, Ganat YM, Wakeman DR, Xie Z, Carrillo-Reid L, Auyeung G, Antonacci C, Buch A, Yang L, Beal MF, Surmeier DJ, Kordower JH, Tabar V, Studer L (2011) Dopamine neurons derived from human ES cells efficiently engraft in animal models of Parkinson's disease. Nature 480, 547-551. Medline

Langmead B, Trapnell C, Pop M, Salzberg SL (2009) Ultrafast and memoryefficient alignment of short DNA sequences to the human genome. Genome Biol 10:R25. CrossRef Medline

Lee G, Kim H, Elkabetz Y, Al Shamy G, Panagiotakos G, Barberi T, Tabar V, Studer L (2007a) Isolation and directed differentiation of neural crest stem cells derived from human embryonic stem cells. Nat Biotech 12:1468-1475.

Lee H, Shamy GA, Elkabetz Y, Schofield CM, Harrsion NL, Panagiotakos G, Socci ND, Tabar V, Studer L (2007b) Directed differentiation and transplantation of human embryonic stem cell-derived motoneurons. Stem Cells 25:1931-1939. CrossRef Medline

Li XJ, Du ZW, Zarnowska ED, Pankratz M, Hansen LO, Pearce RA, Zhang SC (2005) Specification of motoneurons from human embryonic stem cells. Nat Biotechnol 23:215-221. CrossRef Medline

Li XJ, Hu BY, Jones SA, Zhang YS, Lavaute T, Du ZW, Zhang SC (2008) Directed differentiation of ventral spinal progenitors and motor neurons from human embryonic stem cells by small molecules. Stem Cells 26:886893. CrossRef Medline

Liu Y, Zhang SC (2010) Human stem cells as a model of motoneuron development and diseases. Ann NY Acad Sci 1198:192-200. CrossRef

Nédelec S, Peljto M, Shi P, Amoroso MW, Kam LC, Wichterle H (2012) Concentration-dependent requirement for local protein synthesis in motor neuron subtype-specific response to axon guidance cues. J Neurosci 32:1496-1506. CrossRef Medline

Otaegi G, Pollock A, Hong J, Sun T (2011) MicroRNA miR-9 modifies mo- tor neuron columns by a tuning regulation of FoxP1 levels in developing spinal cords. J Neurosci 31:809-818. CrossRef Medline

Palmesino E, Rousso DL, Kao TJ, Klar A, Laufer E, Uemura O, Okamoto H, Novitch BG, Kania A (2010) Foxp1 and Lhxl coordinate motor neuron migration with axon trajectory choice by gating Reelin signalling. PLoS Biol 8, e1000446. CrossRef Medline

Patani R, Hollins AJ, Wishart TM, Puddifoot CA, Ãlvarez S, de Lera AR, Wyllie DJ, Compston DA, Pedersen RA, Gillingwater TH, Hardingham GE, Allen ND, Chandran S (2011) Retinoid-independent motor neurogenesis from human embryonic stem cells reveals a medial columnar ground state. Nat Commun 2:214. CrossRef Medline

Peljto M, Dasen JS, Mazzoni EO, Jessell TM, Wichterle H (2010) Functional diversity of esc-derived motor neuron subtypes revealed through intraspinal transplantation. Cell Stem Cell 7:355-366. CrossRef Medline

Rousso DL, Gaber ZB, Wellik D, Morrisey EE, Novitch BG (2008) Coordinated actions of the forkhead protein Foxp1 and Hox proteins in the columnar organization of spinal motor neurons. Neuron 59:226-240. CrossRef Medline

Singh Roy N, Nakano T, Xuing L, Kang J, Nedergaard M, Goldman SA (2005) Enhancer-specified GFP-based FACS purification of human spinal motor neurons from embryonic stem cells. Exp Neurol 196:224-234. CrossRef Medline

Sinha S, Chen JK (2006) Purmorphamine activates the Hedgehog pathway by targeting Smoothened. Nat Chem Biol 2:29-30. CrossRef Medline

Sockanathan S, Jessell TM (1998) Motor neuron-derived retinoid signaling specifies the subtype identity of spinal motor neurons. Cell 94:503-514. CrossRef Medline

Son EY, Ichida JK, Wainger BJ, Toma JS, Rafuse VF, Woolf CJ, Eggan K (2011) Conversion of mouse and human fibroblasts into functional spinal motor neurons. Cell Stem Cell 9:205-218. CrossRef Medline

Takahashi K, Tanabe K, Ohnuki M, Narita M, Ichisaka T, Tomoda K, Yamanaka S (2007) Induction of pluripotent stem cells from adult human fibroblasts by defined factors. Cell 131:861-872. CrossRef Medline

Takazawa T, Croft GF, Amoroso MW, Studer L, Wichterle H, Macdermott AB (2012) Maturation of spinal motor neurons derived from human embryonic stem cells. PLoS ONE 7:e40154. CrossRef Medline

Thaler JP, Koo SJ, Kania A, Lettieri K, Andrews S, Cox C, Jessell TM, Pfaff SL (2004) A postmitotic role for Isl-class LIM homeodomain proteins in the assignment of visceral spinal motor neuron identity. Neuron 41:337-350. CrossRef Medline

Theys PA, Peeters E, Robberecht W (1999) Evolution of motor and sensory deficits in amyotrophic lateral sclerosis estimated by neurophysiological techniques. J Neurol 246:438-442. CrossRef Medline

Wada T, Honda M, Minami I, Tooi N, Amagai Y, Nakatsuji N, Aiba K (2009) Highly efficient differentiation and enrichment of spinal motor neurons derived from human and monkey embryonic stem cells. PLoS ONE 4:e6722. CrossRef Medline

Watanabe K, Ueno M, Kamiya D, Nishiyama A, Matsumura M, Wataya T, Takahashi JB, Nishikawa S, Nishikawa, S, Muguruma K, Sasai Y (2007) A ROCK inhibitor permits survival of dissociated human embryonic stem cells. Nat Biotechnol 25:681-686. CrossRef Medline

Wichterle H, Lieberam I, Porter JA, Jessell TM (2002) Directed differentiation of embryonic stem cells into motor neurons. Cell 110:385-397. CrossRef Medline 